Portland State University

PDXScholar

1977

\title{
A Quantitative Study Based on a Sonographic Examination of Four Vowel Sounds in Alaryngeal Speech
}

Cheryl Ann Schultz

Portland State University

Follow this and additional works at: https://pdxscholar.library.pdx.edu/open_access_etds

Part of the Speech and Hearing Science Commons, and the Speech Pathology and Audiology

Commons

Let us know how access to this document benefits you.

\section{Recommended Citation}

Schultz, Cheryl Ann, "A Quantitative Study Based on a Sonographic Examination of Four Vowel Sounds in Alaryngeal Speech" (1977). Dissertations and Theses. Paper 2571.

https://doi.org/10.15760/etd.2568

This Thesis is brought to you for free and open access. It has been accepted for inclusion in Dissertations and Theses by an authorized administrator of PDXScholar. Please contact us if we can make this document more accessible: pdxscholar@pdx.edu. 
AN ABSTRACT OF THE THESIS OF Cheryl Ann Schultz for the Master of Science in Speech Communication: Emphasis in Speech Pathology/Audiology presented May 3, 1977.

Title: A Quantitative Study Based on a Sonographic Examination of Four Vowel Sounds in Alaryngeal Speech.

APPROVED BY MEMBERS OF THE THESIS COMMITTEE:
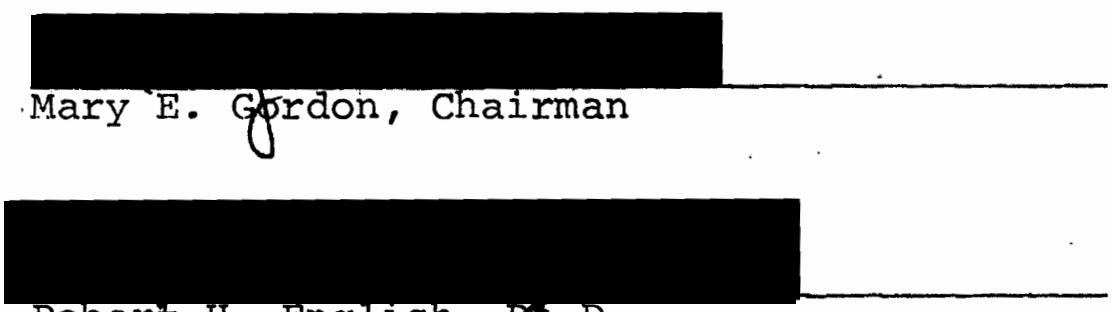

Robert L. Casteel, Ph.D:

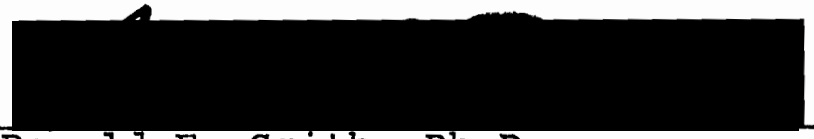

Ronald E. Smith, Ph.D.

Laryngectomy, as a treatment for malignant laryngeal.

lesions, requires the patient to seek a substitute method of producing speech. Three types of alaryngeal speech were described: esophageal, Asai, and artificial larynx. One consideration in deciding which mode of speech is best for the patient is how closely each type of alaryngeal speech approximates normal.

This investigation was an objective examination of 
esophageal, Asai and artificial larynx speech as compared with normal in males and females. Comparisons were based on production of four vowels $/ i /, / 2 z /, / a /, / u /$. Fight subjects were selected, one male and one female in each type of alaryngeal speech. All speakers were recorded producing the four vowels three times. Each production was analyzed sonographically to determine fundamental frequency and formants 1,2 , and 3 .

The following information was obtained to answer the questions posed:

1. What is the difference in fundamental frequency and formants 1, 2, and 3 of four vowels produced by esophageal speakers and normal speakers?

Fundamental frequencies produced by male and female esophageal speakers were 60 and $70 \mathrm{~Hz}$ lower than their normal counterparts, respectively. Formant frequency values for both esophageal speakers showed little relationship to normal, varying both higher and lower in no predictable pattern.

2. What is the difference in fundamental frequency and formants 1, 2, and 3 of four vowels produced by Asai speakers and normal speakers?

The male Asai speaker produced a fundamental frequency approximately $30 \mathrm{~Hz}$ higher than the normal male speaker. Formant 1 was found to be lower than normal; however, this trend did not continue in formants 2 and 3 .

Female Asai fundamental frequency values, only $20 \mathrm{~Hz}$ 
lower than normal, suggest that the Asai technique may provide the female laryngectomee with the closest approximation to normal.

3. What is the difference in fundamental frequency and formants 1,2 ; and 3 of four vowels produced by speakers using electronic vibratory devices and normal speakers? Laryngectomees using an artificial larynx select the. fundamental frequency they desire in operating the mechanical device. These chosen values are considerably lower than normal. As with the other alaryngeal speakers, formant values were scattered above and below normal formant frequencies.

4. What is the difference between male and female production of these vowels in each of the four modes of speech?

Male alaryngeal speakers showed much greater consistency in the production of fundamental frequency over the range of the four vowels. Female alaryngeal speakers varied as much as $53 \mathrm{~Hz}$ from one vowel to another. Artificial larynx speakers are not considered because of the mechanical production of fundamental frequency.

5. What is the difference between esophageal, Asai and electronic vibratory device speakers for the four vowels examined?

Esophageal speakers produce a low fundamental frequency when compared to Asai speakers. Artificial larynx also produces a low fundamental frequency, but this is at the 
discretion of the user. Data on formant frequencies were inconsistent and provided minimal information.

Conclusions derived from this investigation must be guarded due to the small sample population. If the data on these subjects is representative of larger populations, it may be inferred that the fundamental frequency of female Assai speakers is considerably closer to normal than the other two types of alaryngeal speech studied. Male alaryngeal speakers appear to have a broader choice of fundamental frequency ranging above and below normal values.

Further study is suggested on the quantitative aspects of alaryngeal speech using a considerably larger pópulation of subjects. Extreme variations noted in some instances in formant relationships only clarify the need to minimize individual differences through a larger sample. 
A QUANTITATIVE STUDY BASED ON A SONOGRAPHIC EXAMINATION OF FOUR VOWEL SOUNDS

IN ALARYNGEAL SPEECH

$$
\text { by }
$$

CHERYL ANN SCHULTZ

\begin{abstract}
A thesis submitted in partial fulfillment of the requirements for the degree of
\end{abstract}

MASTER OF SCIENCE
in
SPEECH COMMUNICATION: EMPHASIS IN SPEECH PATHOLOGY/AUDIOLOGY

Portland State University

1977 
TO THE OFFICE OF GRADUATE STUDIES AND RESEARCH:

The members of the Committee approve the thesis of Cheryl Ann Schultz presented May 3, 1977.

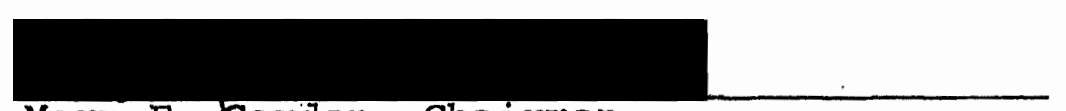

Mary E. Gordon, Chairman

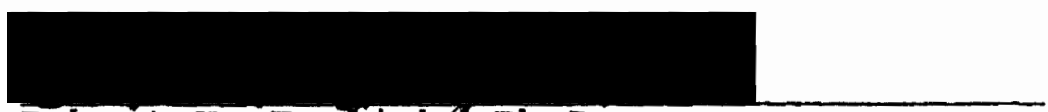

Robert H. Englisb/ Ph.D.

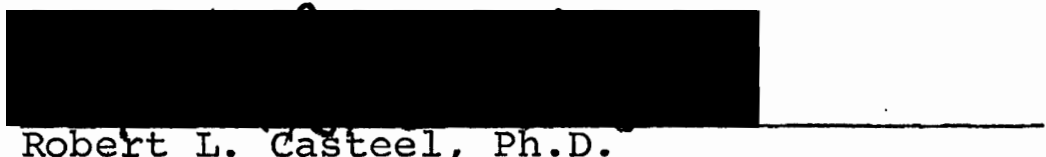

Robert I. Casteel, Ph.D.

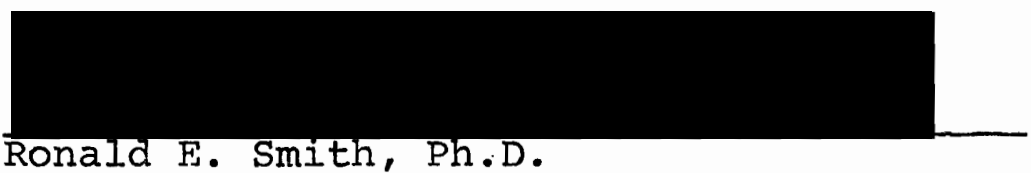

APPROVED:

Rabert W. Vogelffang, Hez/a, Department of Speech Communication

Standey E. Rauch, Dean of Graduate Studies and Research 


\section{ACKNOWLEDGMENTS}

Reflecting back over the events which have ultimately resulted in the completion of this project, certain personalities stand out as being invaluable contributors to the effort.

First and foremost, I must express profound gratitude to my husband, Gary Schultz, for bearing up under what must have been trying periods for him throughout the process of making this project a finished product. He was a sounding board for ideas and frustrations, a traveling companion and equipment bearer during the data collection phase, and most of all a "rock" when I needed support.

Mary Gordon will never know how appreciated her efforts in this endeavor have been. Besides guidance and assistance as thesis Chairperson, she has given friendship during trying times, been understanding of frustrations, and calmed frazzled nerves.

Dr. Robert English must be thanked for allowing himself to be "hassled" all too frequently. His contributions to this project and to my life cannot be expressed.

Dr. Robert Casteel allowed himself to become a sounding board for trying out the ideas which. led to this project. His guidance and help in making it into a workable plan; his 
insights, thoughtfulness, and assistance have been invaluable.

Finally, I must acknowledge gratefully each of the individuals who allowed themselves to be used as subjects for this project. Each offered his time, his hospitality, and many personal insights into the daily life problems and feelings of laryngectomees which cannot be learned from reading research studies or textbooks. They were each warm, willing, eager subjects without whom this project would never have been completed.

To all who participated in this project go my sincerest thanks, and profound gratitude. 
TABLE OF CONTENTS

PAGE

ACKNOWLEDGMENTS . . . . . . . . . . . . . . . iii

IIST OF TABLES . . . . . . . . . . . . . . . . vii

IIST OF FIGURES . . . . . . . . . . . . . . . . viii

CHAPTER

I INTRODUCTION AND STATEMENT OF PURPOSE . . . . I 1

Introduction. . . . . . ..... 1

Statement of Purpose. ......... 2

II REVIEW OF THE LITERATURE. . . . . . . . . 4

Three Types of Alaryngeal Speech. . . . 4

Esophageal Speech

Asai Speech

Artificial Larynx Speech

Quantitative Assessment of Normal

Phonation . . . . . . . . 8

Quantitative Assessment of Alaryngeal

Speech. . . . . . . . . 13

Quantitative Assessment of Esophageal Speech

Quantitative Assessment of Asai Speech

Quantitative Assessment of Artificial Larynx Speech

III METHODS AND PROCEDURES. . . . . . . . 20

General Plan. .......... 20 
Subjects . . . . . . . . . . . . 20

Instrumentation. . . . . . . . . 21

Procedures . . . . . . . . . . . 22

Analysis of Data.. . . . . . . . 23

IV RESULTS AND DISCUSSION • . . . . . . . . . 24

Results. . . . . . . . . . . . 24

Discussion . . . . . . . . . 38

V SUMMARY AND IMPLICATIONS . • • • . . . . 44

Summary. • . . . . . . . . . . 44

Implications . . . . . . . . . . 47

Clinical

Research

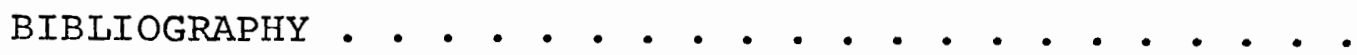

APPENDICES . . . . . . . . . . . . . 54

A: Examples of Sonographic Representation of Normal and Alaryngeal Speakers Production of Vowel / 2 /. . . . . . . . . . . . .

B: Specifications of Kay Sonograph Model $6061 \mathrm{~B}$ and Uher tape recorder, Model 400 Report-I . . . . . . . . . . . . 


\section{LIST OF TABLES}

TABLE

PAGE

I Fundamental Frequencies and Formant Frequencies, Four Cardinal Vowels, Peterson and Barney Study, 1952 . . . . . . . .

II Formant Frequencies 1, 2, and 3, Four Cardinal Vowels, Male and Female Esophageal Speakers, Sisty and Weinberg - 1972. •.

III Formant Frequencies 1, 2, and 3, Normal

Speakers Using Artificial Larynx, Coleman - 1971 . . . . . . . . .

IV Fundamental Frequency and Formant Frequencies 1, 2, and 3, Mean Values for Three Productions of Four Cardinal Vowels. .

V Variability of Frequencies of Formants and Fundamental Frequency - Male subjects. .

VI Variability of Frequencies of Formants and

Fundamental Frequency - Female subjects.

VII Comparison of Normal subjects with Peterson and Barney Subjects - Male Speakers. .

VIII Comparison of Normal subjects with Peterson and Barney Subjects - Female Speakers. . 


\section{LIST OF FIGURES}

FIGURE

PAGE

1 Illustration of Asai Laryngoplasty . . . . .

2 Fundamental Frequencies of vowels $/ \mathrm{d} /, \mathrm{lal}$,

/u/, /i/, Esophageal, Asai, Artificial

Iarynx and Normal Speakers, Male and

Female . . . . . . . . . . . . .

3 Comparison of Alaryngeal speakers to Normal

Speakers on Fundamental and Formant Fre-

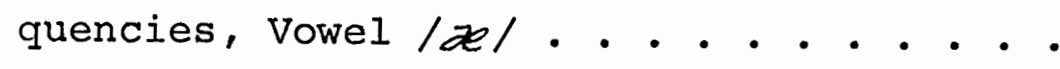

4 Comparison of Alaryngeal Speakers to Normal

Speakers on Fundamental and Formant Fre-

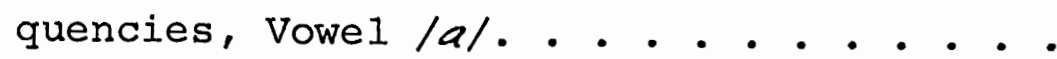

5 Comparison of Alaryngeal speakers to Normal

Speakers on Fundamental and Formant Frequencies, Vowe1/u/. . . . . . . . . .

6 Comparison of Alaryngeal Speakers to Normal

Speakers on Fundamental and Formant Frequencies, Vowel /i/. . . . . . . . . 


\author{
CHAPTER I \\ INTRODUCTION AND STATEMENT OF PURPOSE
}

INTRODUCTION

In the presence of malignant laryngeal lesions, the patient's health and preservation of life become the paramount considerations in medical intervention, and to these ends the ability to produce voice is sacrificed. According to Perkins (1971), "a total laryngectomy involves the excision of the entire larynx from the trachea to the base of the tongue, often including the hyoid bone." With the elimination of voice, the patient's main task becomes the development of a substitute communication method as a replacement for his excised vocal capabilities. Numerous vocal substitutes are possible for the laryngectomee, including esophageal speech, electronic vibratory devices commonly referred to as artificial larynx, and surgical laryngoplasty resulting in the use of Asai speech.

Boone (1971) reported that while laryngeal cancer may befall an individual of any age, its most frequent victims are in their fifties and sixties. Incidence of laryngectomy among males is much higher than among females, with males accounting for 18,600 of the 23,000 cases as reported by snidecor (1971). Laryngectomy surgery is performed with a 
survival rate of about 3,000 per year, adding substantially to those 23,000 cases reported alive in the United States in 1968 (Snidecor, 1971). According to the National Cancer Institute, there has been a 75 percent increase in laryngeal cancer in the past decade, but the mortality rate has risen 42 percent (Diedrich and Youngstrom, 1966). With survival, comes the need to develop a new means of communication. Approximately 60 to 70 percent of the laryngectomy patients attempting to learn esophageal speech meet with success, according to Snidecor (1971). While these figures can be encouraging to the prospective laryngectomee, what of the 30 to 40 percent who do not acquire the skills of esophageal speech? For them, there is a great need to find an alternative to esophageal speech. Two possibilities are surgical laryngoplasty and the electronic vibratory device.

When considering alternative modes of speech, both objective and subjective elements must be explored by patient and physician. Much has been written about the subjective aspects of alaryngeal speech (Snidecor, 1968, 1971), but little research has been reported on objective characteristics.

\section{STATEMENT OF PURPOSE}

The purpose of this investigation was to identify quantitatively those modes of alaryngeal speech which most closely approximate "normal" speech in the voice parameters measured. 
This investigation was undertaken to objectively assess certain quantitative aspects of three alaryngeal speech methods. The four cardinal vowels / $a, x, u, i /$ produced by esophageal speech; Asai speech following surgical laryngoplasty; an electronic vibratory device; and normal speech were examined sonographically to identify the fundamental frequency of each mode of voice production, as well as the identification of frequencies of formants 1,2 , and 3 .

The specific questions this investigation sought to answer were:

1. What is the difference in fundamental frequency and formants 1,2 , and 3 of four vowels produced by esophageal speakers and normal speakers?

2. What is the difference in fundamental frequency and formants 1,2 , and 3 of four vowels produced by Asai speakers and normal speakers?

3. What is the difference in fundamental frequency and formants 1,2 , and 3 of four vowels produced by speakers using electronic vibratory devices and normal speakers?

4. What is the difference between male and female production of these vowels in each of the four modes of speech?

5. What is the difference between esophageal, Asai and electronic vibratory device speakers for the four vowels examined? 
CHAPTER II

REVIEW OF THE LITERATURE

When patients undergo a total laryngectomy, no laryngeal structure remains; thus, breathing must be accomplished via a tracheostoma formed at the top of the trachea and protruding out through the lower neck at the midline. Following surgery the patient is left without the capability of producing voice. Selection of a substitute voice for the laryngectomee will take into consideration the following:

THREE TYPES OF ALARYNGEAL SPEECH

Esophageal Speech

Esophageal speech has become the preferred method of alaryngeal speech in approximately 64 percent of 3,366 laryngectomized patients surveyed by the American Cancer Society (Diedrich and Youngstrom, 1966). While three separate methods exist for producing esophageal speech, the majority of esophageal speakers employ the "injection method" (Boone, 1971). This method requires the speaker to use his tongue as a driving mechanism, trapping air between tongue, hard and soft palates, and pharynx. The compressed air is forced backward into the hypopharynx and into the open esophagus where it is entrapped for phonation (Boone, 1971). Air 
trapped in the esophagus then is expelled, activating vibratory movement of the pharyngo-esophageal junction, which is thought to be largely comprised of the cricopharyngeus muscle; there sound is produced (Perkins,1971). Using the normal processes of resonation and articulation, the esophageal speaker is able to produce intelligible speech in this manner.

\section{Asai Speech}

Asai speech was named for the Japanese laryngologist, Ryozo Asai, who pioneered the surgical technique. It was first reported to the medical world in october, 1965, at the Eighth International Congress of Otorhinolaryngology in Tokyo, Japan.

Asai laryngoplasty is usually accomplished in three stages or operations. The entire technique is designed to create a dermal tube buried under the skin at the anterior midline of the neck. This tube reaches from the upper end of the remaining tracheal tube into the hypopharynx (see Figure 1). With surgery completed, the patient is able to occlude the permanent tracheostoma used for breathing, thereby shunting expired air up through the dermal tube producing sound as the passing air sets up a vibration of the walls of the dermal tube. From the tube, sound proceeds into the oral and nasal cavities for articulation and resonation, thus creating speech. Immediately following the third stage of surgery to imbed the dermal tube, this speech produc- 


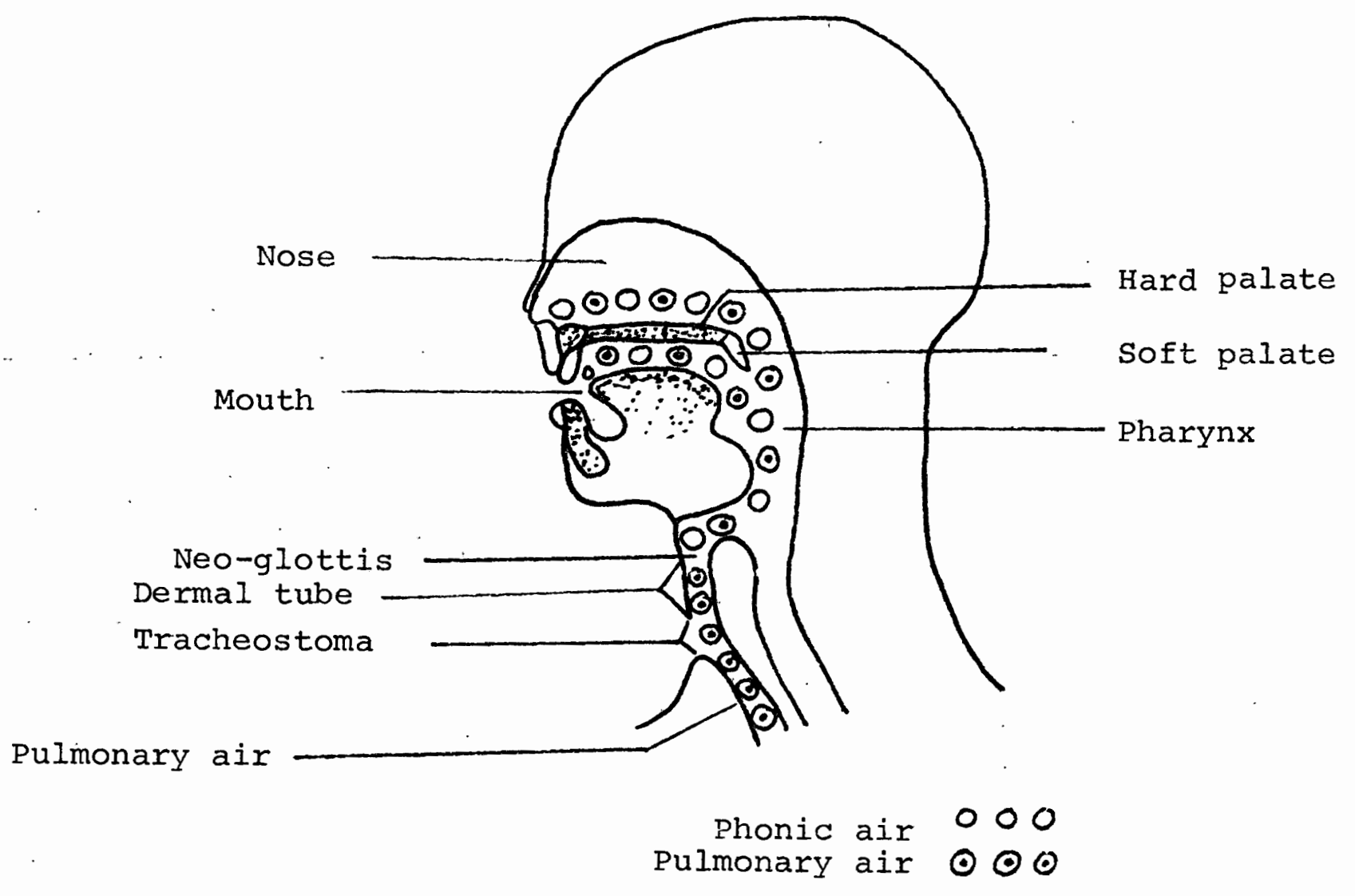

Figure 1. The head and neck after Asai surgery (modified from Snidecor, 1971). 
tion process may be performed by the patient as Asai speech does not require a training period (Miller, 1971). Using expelled pulmonary air and directing it through the dermal tube with digital occlusion of the tracheostoma, a substitute voice is available to the patient without delay.

\section{Artificial Larynx Speech}

Though several models of artificial larynges are available to the patient, the Western Electric Electrolarynx is widely used. This handheld device, with its vibrator at one end, is placed firmly against the neck in the area of the hypopharynx. A pushbutton control operated by the thumb results in sound production. These sound vibrations penetrate the hypopharyngeal skin to enter the vocal tract for resonation and articulation for speech (Boone, 1971).

A training period is necessary before the patient will be adept at speaking with an artificial larynx. He must learn proper placement of the instrument for his own best sound, as this varies from patient to patient. Additionally, he must learn to articulate consonants with no pulmonary airflow, thus, necessitating some minor changes in his articulatory patterns. Finally, he must learn to coordinate his operation of the on-off switch with the flow of speech to avoid excesses of noise, i.e., sound production between phrases or utterances (Boone, 1971). Following the training process the patient has speech available without the need for breath support. Thus, many 
esophageal patients use the artificial larynx as a back-up during training or when fatigued. Boone (1971) and Diedrich and Youngstrom (1966) view esophageal speech and artificial larynx speech as compatible to provide the laryngectomee with a ready speech source for all occasions.

\section{QUANTITATIVE ASSESSMENT OF NORMAL PHONATION}

Vocal fold vibration in the normal larynx may produce a wide variety of tones. Fairbanks (1960) indicated relaxed, normal phonation may vary in one person; covering a range of nearly two octaves. Normally, however, an individual's pitch is distributed in such a manner as to indicate a definite central tendency (Zemlin, 1968).

When expressed in cycles per second (hereafter called Hertz and expressed $\mathrm{Hz}$ ), the fundamental frequency may be derived as a direct result of the number of times per second the vocal folds vibrate (Kaplan, 1971). Kaplan (1971) has indicated the usual range of fundamental frequency is from 100 to $400 \mathrm{~Hz}$, with variations being the result of variations in the length (Hollien, 1960) and thickness (Boone, 1971; Hollien, 1962; Hollien and Curtis, 1960) of each individual's vocal folds.

With vocal fold length of approximately $18 \mathrm{~mm}$ (Boone, 1971) to between $23 \mathrm{~mm}$ and $27 \mathrm{~mm}$ (Gray and wise, 1959), the adult male fundamental frequency is reported to be approximately $125 \mathrm{~Hz}$ to $130 \mathrm{~Hz}$ (Boone, 1971; Zemlin, 1968). Peter- 
son and Barney (1952) found average fundamental frequencies for two vowel sounds to range from $124 \mathrm{~Hz}$ on $/ a /$ to $141 \mathrm{~Hz}$ on $/ u /$ in adult males. Mysak (1959) found, in addition to slight variations in fundamental frequency depending on whether the task was reading or impromptu speaking, there was evidence of male pitch rising with age. His results indicated that in the middle-aged group (32 to 62 years, mean age 47.9 years) the average fundamental frequency was $107.9 \mathrm{~Hz}$. In the elderly group ( 65 years to 79 years, mean age 73.3 years), the average fundamental frequency had risen to $120.0 \mathrm{~Hz}$. In the very elderly group $(80$ years to 92 years, mean age 85.0 years), the average fundamental frequency had risen further to $137.1 \mathrm{~Hz}$. Each of these values is for impromptu speaking, with reading values found to be 3 to $5 \mathrm{~Hz}$ higher. Mysak (1959) attributed the noted changes to multiple factors, primarily changes in the laryngeal structure.

Female vocal folds are considerably shorter than those of the male. Boone (1971) reported them to be $10 \mathrm{~mm}$ in length, while Gray and wise (1959) found them to be fivesevenths the length of the male folds, or approximately 16 to $19 \mathrm{~mm}$. The shorter female vocal folds result in a higher frequency tone production, ranging from $210 \mathrm{~Hz}$ on $/ 2 /$ to $235 \mathrm{~Hz}$ on / $i /$ in the Peterson and Barney (1952) study. zemlin (1968) reported $260 \mathrm{~Hz}$ as contrasted with Boone's (1971) finding of $200 \mathrm{~Hz}$. 
Accompanying the production of the fundamental frequency are overtones produced by segmental vibration of the vocal folds which occur simultaneously with the production of the fundamental frequency (Hanley and Thurman, 1962). Thus, the vocal tone at the level of the larynx is a complex tone.

As the tone is transmitted through the pharynx and oral cavities resonation occurs, damping some frequencies while enhancing others. Articulatory movements create a particular set of resonating surfaces and cavities to produce a given phoneme. The articulators are capable of creating ". . a whole series of resonant frequencies (Bogert and Peterson, 1957)." It is the standardization of these articulatory movements to specific cavity sizes and shapes which provide the concentrations of energy at certain frequencies to make each phoneme unique (Bogert and Peterson, 1957; Hanley and Thurman, 1962).

To quantitatively assess voice production, the spectrograph was designed to analyze speech in its acoustical form (Gray and Wise, 1959). A graphic illustration is obtained of the formants present in a sample of speech. (Appendix A. illustrates sonographic representations of the vowel $/ \mathcal{X l} /$.) Gray and wise (1959) define the term formant after Fletcher as consisting of:

. . two (sometimes three, seldom one) frequency regions of prominence in the speech sound as observed in the outside air. The frequency locations of these regions of accentuated intensity, known as formants, 
are an important characteristic lending individuality to the various periodic sounds.

The acoustic representation of a formant is tied to the physiologic structures directly, stated Gray and wise (1959):

. . it is the existence in the vocal tract of these two major resonating cavities (pharyngeal and oral), together with the narrow passages connecting them with each other and with the external air, that produces the 'frequency regions of prominence' in the speech sounds, and differentiates them one from another.

They further stated ". . . each of these cavities thus created, the throat and the mouth, produces one formant, the coupling between them probably producing another (Gray and Wise, 1959). Potter and Steinberg (1950) supported this view stating that the ". . formant frequencies for a given vowel are probably directly related to the dimensions of the vocal cavities."

Froeschels (1948) noted that the theory of Helmholtz (and Stumpf) indicates ". . each vowel consists of a basic tone and several harmonic partial tones, the so-called overtones." Further, Stumpf is reported to state ". . some of the over-tones are especially loud (formants) and that these have to be present in the tone mixture in order that the vowel in question will be recognized (Froeschels, 1948)." Denes and Pinson (1963) indicated that ". . usually the first three or four formant frequencies are adequate for recognition."

Thus, for each individual phoneme one can expect to 
see, via spectrographic analysis, a unique and rather constant set of formants based on the standard articulatory movements required to make that phoneme identifiable.

With individual differences in cavity shape and size, it is difficult for two different vocal tracts to produce matching sounds. Potter and Peterson (1948) suggested formant relationships, rather than exact frequency match, may be responsible for determining vowel sounds.

Formant frequencies of vowel sounds produced by 76 speakers were studied by Peterson and Barney (1952). For purposes of this investigation, the data in Table I excerpted from that study are of significance.

It may be noted from the data that the ratios among formants appear to remain ". . fairly constant over the range of speakers (Peterson and Barney, 1952)."

\section{TABLE I}

FUNDAMENTAL FREQUENCIES AND FORMANT FREQUENCIES FOUR CARDINAI VOWELS PETERSON AND BARNEY STUDY

\section{2}

\begin{tabular}{lrrrr}
\hline \hline Adult Males & $/ i /$ & $/ \not e /$ & $/ a /$ & $/ \mathrm{u} /$ \\
\hline Fundamental Frequency & 136 & 127 & 124 & 141 \\
Formant 1 & 270 & 660 & 730 & 300 \\
Formant 2 & 2290 & 1720 & 1090 & 870 \\
Formant 3 & 3010 & 2410 & 2440 & 2240 \\
\hline Adult Females & $/ \mathrm{i} /$ & $/ 2 e /$ & $/ a /$ & $/ \mathrm{u} /$ \\
Fundamental Frequency & 235 & 210 & 212 & 231 \\
Formant 1 & 310 & 860 & 850 & 370 \\
Formant 2 & 2790 & 2050 & 1220 & 950 \\
Formant 3 & 3310 & 2850 & 2810 & 2670 \\
\hline
\end{tabular}




\section{QUANTITATIVE ASSESSMENT OF ALARYNGEAL SPEECH}

Quantitative Assessment of Esophageal Speech

With the excision of the larynx and the implementation of esophageal speech, gross changes in frequency values would be expected. Probably due to the statistical preponderance of male laryngectomees (Snidecor, 1968), most studies have dealt with male esophageal speakers. Thus, specific data on female voices are limited.

Fundamental frequency values characteristically shift downward in esophageal speech. Snidecor and Curry (1961) reported a mean fundamental frequency for six esophageal speakers of $62.8 \mathrm{~Hz}$. Rollin, in an unpublished dissertation cited by Curry (1960), found a mean fundamental frequency of 65.6 Hz for ten speakers. Shipp (1967), in a study of the acceptability of esophageal speech, found the mean fundamental frequency of what he termed "six best speakers" of thirty-three subjects to be $94.38 \mathrm{~Hz}$. His group judged to be of lower acceptability $(N=16)$ were found to have a mean fundamental frequency of $64.74 \mathrm{~Hz}$, in contrast to a group rated as more acceptable $(\mathrm{N}=17)$ whose mean fundamental frequency was $84.4 \mathrm{~Hz}$.

The Shipp data may not be directly comparable to the data previously cited due to a difference in measurement technique. Shipp used a wave-by-wave assessment technique; whereas, Snidecor, Curry and the others employed an averaging technique. This discrepancy results in slight variations in 
the final outcome (Weinberg and Bennett, 1972). Regardless of the method of measurement employed, the general trend downward in fundamental frequency is definitely present. Weinberg and Bennett (1972) divided their sample population of esophageal speakers into categories of male and female to determine mean fundamental frequency. Results indicated a difference between male and female, with eighteen males averaging $58 \mathrm{~Hz}$, and fifteen females averaging $87 \mathrm{~Hz}$. Their combined mean fundamental frequency was $69 \mathrm{~Hz}$. Again, this study employed a wave-by-wave rather than averaging technique in measurement. Thus, these results are not totally comparable to those of Curry and Snidecor or Rollin. The Weinberg and Bennett (1972) data suggest a significant difference in the esophageal speech production of males and females. Snidecor and Curry (1960) attempted to have a panel of judges identify female esophageal voices from a mixed group of recorded male and female esophageal voices. No success was found in the subjective task; hence, snidecor and Curry concluded there was a great similarity between male and female esophageal voices.

While most acoustic data relative to esophageal speech have dealt with the fundamental frequency, Sisty and Weinberg (1972) investigated vowel formant frequencies in fourteen male and thirteen female esophageal speakers. Pertinent to the current study, their results for selected vowels are as follows : 
TABLE II

FORMANT FREQUENCIES 1, 2, AND 3 FOUR CARDINAI VOWELS

MALE AND FEMALE ESOPHAGEAL SPEAKERS

SISTY AND WEINBERG - 1972

\begin{tabular}{lrrrr}
\hline Males & $/ \mathrm{i}$ & $/$ el & $/ a /$ & $/ \mathrm{u}$ \\
\hline Formant 1 & 401 & 791 & 984 & 459 \\
Formant 2 & 2684 & 2059 & 1357 & 1213 \\
Formant 3 & 3067 & 2762 & 2830 & 2666 \\
\hline & $/ \mathrm{i}$ & $/ 2 /$ & $/ a /$ & $/ \mathrm{u} /$ \\
Females & 390 & 908 & 1031 & 435 \\
Formant 1 & 2925 & 2412 & 1432 & 1134 \\
Formant 2 & 3627 & 3106 & 3012 & 2835 \\
Formant 3 & & & &
\end{tabular}

When these values are compared with the Peterson and Barney data (1952), the formant frequencies for esophageal speakers are consistently higher. Sisty and Weinberg (1972) found an average increase in males on $\mathrm{F}_{1}$ of $122 \mathrm{~Hz}, \mathrm{~F}_{2}$ of $325 \mathrm{~Hz}$, and $\mathrm{F}_{3}$ of $321 \mathrm{~Hz}$ when compared to Peterson and Barney's. (1952) normal group. Females in the study also demonstrated a systematic rise in formant frequency. Female average increases were $76 \mathrm{~Hz}$ on $\mathrm{F}_{1}, 2 \mathrm{ll} \mathrm{Hz}$ on $\mathrm{F}_{2}$, and $208 \mathrm{~Hz}$ on $\mathrm{F}_{3}$, again as compared with Peterson and Barney (1952).

From these comparisons, it becomes apparent that excision of the larynx does indeed alter the transmissive characteristics of the vocal tract. While Sisty and Weinberg (1972) do not feel this change can be fully explained on the basis of altered tongue positioning or mouth opening, they do suggest the possibility of these alterations being explained on the basis of a ". . reduction in the effective 
length of the vocal tract as a result of total laryngectomy surgery." The altered vocal tract apparently serves to elevate the formant frequencies. This position can be supported by the Diedrich and Youngstrom (1966) data which cinefluorographically illustrated the post-operative reduction in the vocal tract length as compared to its pre-operative state. Evidence collected on esophageal speech suggests that when the larynx is excised and esophageal speech substituted for normal voice, variations will be noted in fundamental frequency and formant frequencies. The fundamental frequency appears to be lowered, due to the mass and size of the neoglottis while the trend for formant values is upward due to altered size and shape of the resonating cavities.

Quantitative Assessment of Asai Speech

The phonatory capabilities available to the patient who has undergone Asai reconstruction following laryngectomy have not been fully investigated for trends in fundamental and formant frequencies. Curry and snidecor (1973) noted several of the characteristics of Asai speech included higher pitch, more rapid, and breathier than esophageal speech. To study fundamental frequency, five Japanese Asai speakers, speaking Colloquial Japanese, were selected as subjects. They were asked to read a passage which was very closely compared with American dialect in language and voiced/voiceless structure, and, therefore, felt to be compatible for making cross-language comparisons. Curry and snidecor (1973) 
determined the average fundamental frequency of five subjects was $97.08 \mathrm{~Hz}$. Contrasted with the reported data on esophageal speakers, this represents a trend toward the mean fundamental frequency of normal speakers. Three males in the group demonstrated mean fundamental frequencies of $96 \mathrm{~Hz}, 124 \mathrm{~Hz}$, and $80 \mathrm{~Hz}$ respectively. Note that one of the three male Asai speakers produced a mean fundamental frequency comparable to the mean fundamental frequency of normal male speakers in the Peterson and Barney study (1952). The two female speakers using Asai voice exhibited mean fundamental frequencies of 150 and $81 \mathrm{~Hz}$ respectively. These values are widely variant, one falling above the mean for normal male speakers, the other falling below the normal male mean. Neither of the female Asai speakers produced a mean fundamental frequency comparable to the Peterson and Barney (1952) normal female speakers.

Formant frequencies for Asai speakers have not been reported in the literature. From the data available on fundamental frequency, it appears that Asai speakers more closely approximate normal fundamental frequency than do esophageal speakers. Much further research is needed in the area of Asai speech before conclusions can be made.

Quantitative Assessment of Artificial Larynx Speakers

Little investigation of voice production via the use of an artificial larynx has been done. While attitudes are 
changing, the artificial larynx was not considered a desirable substitute for normal voice until recently (Boone, 1971). Control of the fundamental frequency is accomplished by a manual setting on the instrument, thereby making investigation of that parameter of artificial larynx speech unnecessary .

Coleman (1971), in a study employing normal speaking adult subjects, 10 male and 10 female, spectrographically investigated the effect of using the artificial larynx (specifically the Western Electric Company, Model 5, Electrolarynx). Fundamental frequency was set at $85 \mathrm{~Hz}: 3 \mathrm{~Hz}$ for all subjects. Formant frequencies were obtained for vowels / $i /$ and / $u /$. Results are shown in Table III:

In addition, Coleman (1971) obtained listener judgments on maleness and femaleness. He found judges were able. to correctly identify male and female voices 88 percent of the time. He suggested the cue to these distinctions lies in the vocal tract resonances of the speaker.

\section{TABLE III}

FORMANT FREQUENCIES 1,2 , AND 3 NORMAL SPEAKERS USING ARTIFICIAL LARYNX COLEMAN - 1971

\begin{tabular}{|c|c|c|c|c|c|}
\hline Male & $|i|$ & $/ \mathrm{u} /$ & Female & /i/ & $/ \mathrm{u} /$ \\
\hline $\begin{array}{ll}\text { Formant } 1 \\
\text { Formant } 2 \\
\text { Formant } 3\end{array}$ & $\begin{array}{r}290 \\
2400 \\
3270\end{array}$ & $\begin{array}{r}356 \\
1075 \\
2639\end{array}$ & $\begin{array}{ll}\text { Formant } 1 \\
\text { Formant } 2 \\
\text { Formant } 3\end{array}$ & $\begin{array}{r}343 \\
2707 \\
3454\end{array}$ & $\begin{array}{r}408 \\
1019 \\
2932\end{array}$ \\
\hline
\end{tabular}


Since this research was conducted using normal laryngeal speakers, caution must be exercised in directly translating the results to compare with alaryngeal speakers whose vocal tract has been altered considerably. 
CHAPTER III

METHODS AND PROCEDURES

\section{GENERAL PLAN}

This study investigated the variations in fundamental and formant frequencies 1, 2, and 3, for three types of alaryngeal speakers, and a control group of normal speakers. A spectrographic analysis of four vowel sounds (/みe, $a, u, i /$ ) produced by each speaker was performed from data recorded on a high-fidelity tape recorder.

\section{$\underline{\text { SUBJECTS }}$}

Subjects for this investigation included the following: 1. Two adults (one male and one female) who had undergone Asai reconstructive surgery following laryngectomy and used Asai speech as their principle form of oral communication. The male Asai speaker was aged 62 at the time of recording and had used Asai speech for four months. The female Asai speaker was 56 years of age and had used Asai speech eight years prior to recording. Both subjects lived in the Los Angeles area.

2. Two adults (one male and one female) who had undergone total laryngectomy and used esophageal speech as their principle form of oral communication. The male esophageal 
speaker was 52 years old at the time of recording, and had used esophageal speech for ten years. The female esophageal speaker was 56 years old and the exact length of time she had used esophageal speech is not known. The male esophageal speaker lived in Los Angeles, and the female esophageal speaker lived in Portland, Oregon.

3. Two adults (one male and one female) who had undergone total laryngectomy and used an artificial larynx as their principle form of oral communication. The male artificial larynx speaker was 72 years of age and it is not known how long he had used artificial larynx speech prior to recording. The female artificial larynx speaker was 52 years old and had used that form of communication for 19 years. Both artificial larynx speakers lived in the Los Angeles area.

4. Two adults (one male and one female) who are normal laryngeal speakers. They exhibited no current voice or speech abnormalities, nor had any abnormalities in their history. Both normal speakers were 63 years of age at the time of recording.

\section{INSTRUMENTATION}

A Uher tape recorder, model 4000 Report-I (see specifications in Appendix B-2), with accompanying microphone, was used to record each voice sample on Ampex tape, type 651. The recorder was operated at $33 / 4$ inches per second. 
This machine was selected for recording because of its portability, as several subjects were recorded in Los Angeles and others in Portland, Oregon.

The taped vowel productions were played into the Kay Sonograph, Model 6061B (specifications are reported in Appendix B-1) using a Type A display illustrating frequency plotted on the ordinate and time on the abscissa. A Type B display was subsequently overlayed on the graphic display to indicate the relative intensity of each frequency represented in the Type A display.

\section{PROCEDURES}

Each of the following monosyllabic words were produced three times by each subject: /tip/, /tup/, /tæep/,/tap/. These vowel sounds were chosen because they are the corner vowels on the standard vowel chart. The vowel portion of each monosyllabic word was elongated as demonstrated by this investigator. Consonants $/ t /$ and $/ p /$ were selected as the acoustic environment for the vowels because both are voiceless and would isolate the vowel formants. In addition / $t /$ is easy for alaryngeal speakers to produce in initiating phonation.

The microphone was held $6-8$ inches in front of the mouth at the level of the chin. All recordings were made in the subjects' homes with efforts made to eliminate background noise. 
The specific instructions given verbally to the subjects were:

I am going to tape record your voice as you say these words: /tip/, /tup/, /tæep/, /tap/. I want you to say each word three times in a row and say them just the way I do.

A model was then presented demonstrating each monosyllabic word, elongating the vowel portion approximately one second. The model was as follows: "/tip/, /tip/, /tip/." The model was followed by "Let's practice them before we record." Recordings were made after the subject demonstrated he could elongate the vowel to approximately one second in length.

\section{ANALYSIS OF DATA}

All vowel productions were analyzed spectrographically to determine fundamental frequency and the first, second, and third formant frequencies. Three productions of each vowel were analyzed for each speaker, the values averaged and expressed as the "mean fundamental frequency" and "mean formant frequencies."

After mean values for each vowel produced by each speaker were found these values were compared to answer questions posed in Chapter I. The mean values for each vowel were graphically compared among the four groups. 
CHAPTER IV

RESULTS AND DISCUSSION

\section{RESULTS}

The purpose of this investigation was to objectively assess certain quantitative aspects of alaryngeal speech. Four vowels produced by esophageal speech, Asai speech and electronic vibratory device (artificial larynx) speech were examined to determine their relationship to normal speech production in both fundamental frequency and the frequencies of formants 1, 2, and 3 . In addition, the variability of these parameters within the three modes of alaryngeal speech was examined.

To determine fundamental frequencies and frequencies of formants 1, 2, and 3 for each speaker, a taped sequence of vowels was analyzed sonographically. Each vowel was within the context of a monosyllable word (e.g.: / / and each word was produced three times to provide mean values for fundamental, as well as formant frequencies, for each speaker. The four vowels represented in this investigation were the four corner (cardinal) vowels on the standard vowel chart; thus, extremes of production from high front to low back focus within the oral cavity were present. To respond to each of the questions posed in Chapter I, 
data were separated into productions by male and female subjects in order to eliminate intrinsic sex-linked differences in voice production. No conclusions may be drawn from the data gathered that would reflect characteristics of voice production for a general population of alaryngeal speakers or for normal speakers because the size of the sample population was not sufficient to minimize individual differences in voice production. These data reflect characteristics of voice only for the eight subjects examined.

The resulting mean values of the fundamental frequency and formants 1,2 , and 3 are shown in Table IV for each vowel by each speaker. The data provide comparative information on each form of alaryngeal speech with normal speakers participating in this study. All data are expressed in Hertz (Hz) for fundamental or formant frequency indicated. Spaces in the charts marked with an asterisk (*) indicate that no data were collected on these items. The same data on fundamental frequencies is illustrated in Figure 2. Figures 3 through 6 illustrate relationships of male and female alaryngeal speakers to normal performance on each vowel. Variability of each speaker among three productions of the same vowel is shown on Tables $V$ and VI. It can be seen that all speakers varied in the formant frequencies of vowel productions; however, with a few notable exceptions, this variation seemed to be minimal.

Comparison of male alaryngeal speech to normal male 
TABLE IV

FUNDAMENTAL FREQUENCY AND FORMANT FREQUENCIES 1, 2, AND 3 MEAN VALUES FOR THREE PRODUCTIONS OF FOUR CARDINAL VOWELS

\begin{tabular}{|c|c|c|c|c|c|c|c|c|c|}
\hline \multicolumn{5}{|c|}{ MALE SPEAKERS } & \multicolumn{5}{|c|}{ FEMALE SPEAKERS } \\
\hline SPEAKER & $\mathrm{F}_{0}$ & $\mathrm{~F}_{1}$ & $\mathrm{~F}_{2}$ & $\mathrm{~F}_{3}$ & SPEAKER & $\mathrm{F}_{0}$ & $\mathrm{~F}_{1}$ & $\mathrm{~F}_{2}$ & $\mathrm{~F}_{3}$ \\
\hline \multicolumn{10}{|l|}{ Vowel /i/ } \\
\hline Esophageal & 65 & 333 & 1016 & 2133 & Esophageal & 112 & 250 & 3125 & * \\
\hline Asai & 160 & 550 & 1366 & 2033 & Asai & 192 & 408 & 3183 & 3550 \\
\hline A. I. & 104 & 325 & 900 & 2466 & A. I. & 80 & 400 & 2733 & 3366 \\
\hline Normal & 138 & 275 & 2358 & 3100 & Normal & 221 & 350 & 2700 & 3216 \\
\hline \multicolumn{10}{|l|}{ Vowel / X/ } \\
\hline Esophageal & 72 & 1000 & 2066 & 3250 & Esophageal & 165 & 800 & 2441 & 3600 \\
\hline Asai & 168 & 916 & 1500 & 2333 & Asai & 168 & 783 & 2316 & 3283 \\
\hline A. L. & 98 & 800 & 1433 & 2200 & A. I. & 80 & 858 & 2313 & 3216 \\
\hline Normal & 128 & 741 & 1850 & 2733 & Normal & 189 & 833 & 2200 & 2800 \\
\hline \multicolumn{10}{|l|}{ Vowel /a/ } \\
\hline Esophageal & 74 & 450 & 1100 & 1683 & Esophageal & 125 & 333 & 1166 & 1575 \\
\hline Asai & 170 & 916 & 1566 & * & Asai & 162 & 850 & 1783 & 3300 \\
\hline A. L. & 98 & 866 & 1533 & 2150 & A. I. & 80 & 616 & 1433 & 3300 \\
\hline Normal & 120 & 716 & 1300 & 2600 & Normal & 192 & 933 & 1416 & * \\
\hline \multicolumn{10}{|l|}{ Vowel /u/ } \\
\hline Esophageal & 72 & 383 & 1116 & 2450 & Esophageal & 128 & 408 & 1108 & 2141 \\
\hline Asai & 157 & 700 & 1600 & * & Asai & 197 & 300 & 1166 & 1983 \\
\hline A. I. & 104 & 483 & 1150 & 2641 & A. L. & 80 & 533 & 983 & 3033 \\
\hline Normal & 130 & 300 & 1300 & 2250 & Normal & 208 & 383 & 1466 & 2783 \\
\hline
\end{tabular}



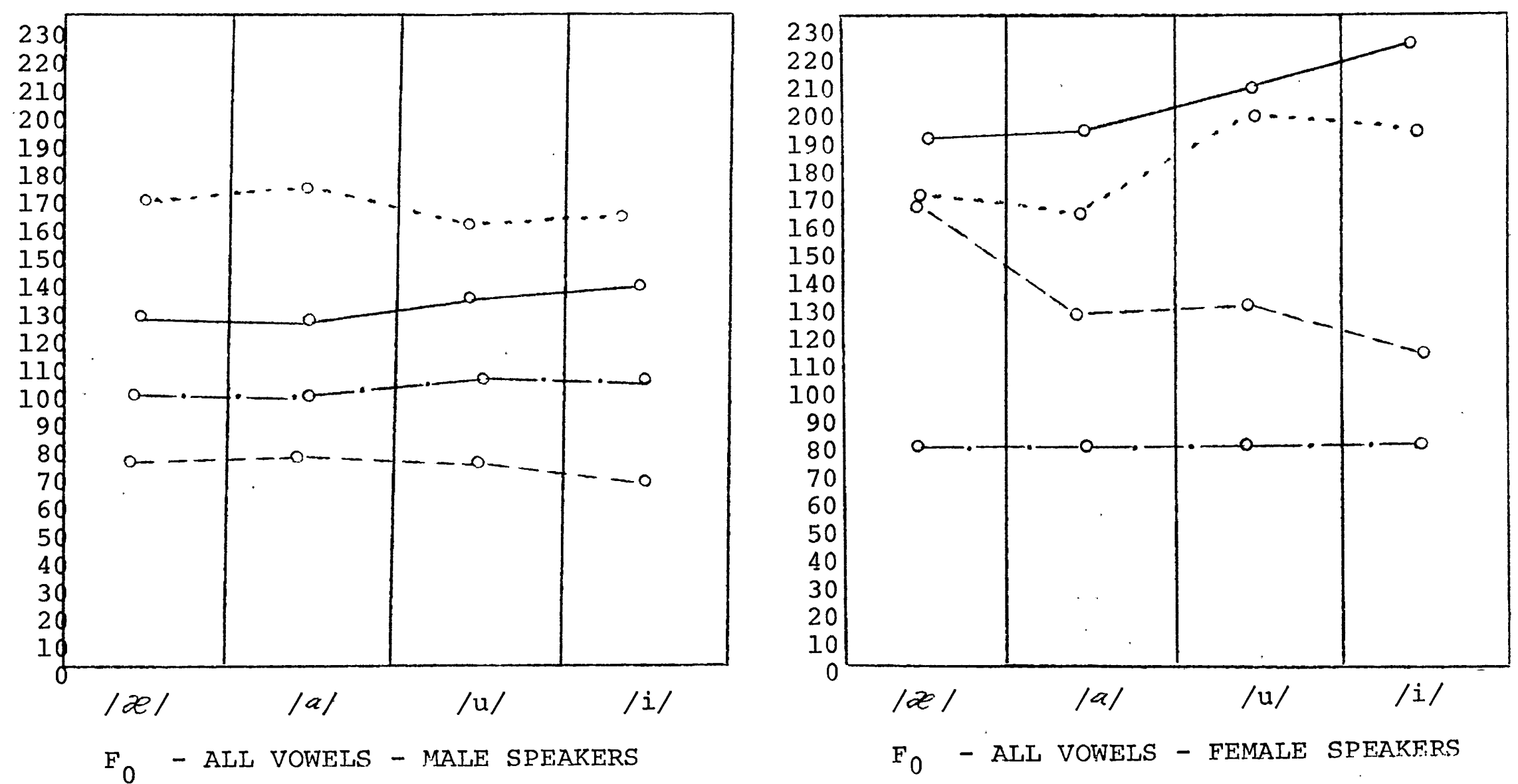

Legend: Normal Speakers

- - Esophageal Speakers

.... Asai speakers

- Artificial Larynx Speakers

Figure 2. Fundamental Frequencies of Vowels / $/ /, / a /, / u /, / i /$ Esophageal, Asai, Artificial Larynx and Normal Speakers Male and Female 

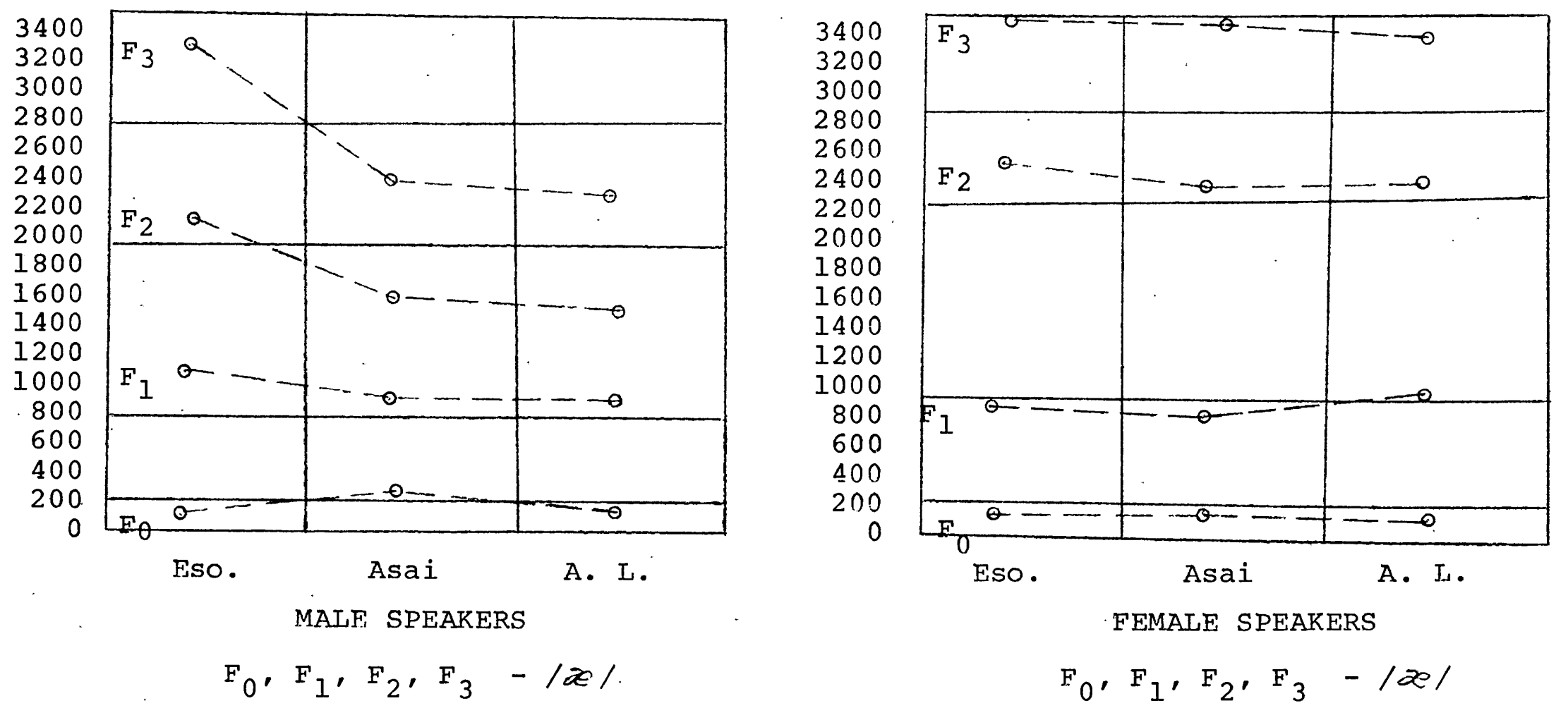

Note: Connecting lines denote normal speaker's. frequency for $F_{0}, F_{1}, F_{2}, F_{3}$

Figure 3. Comparison of Alaryngeal Speakers to Normal speakers on Fundamental and Formant Frequencies, Vowel / $/$ e/. 


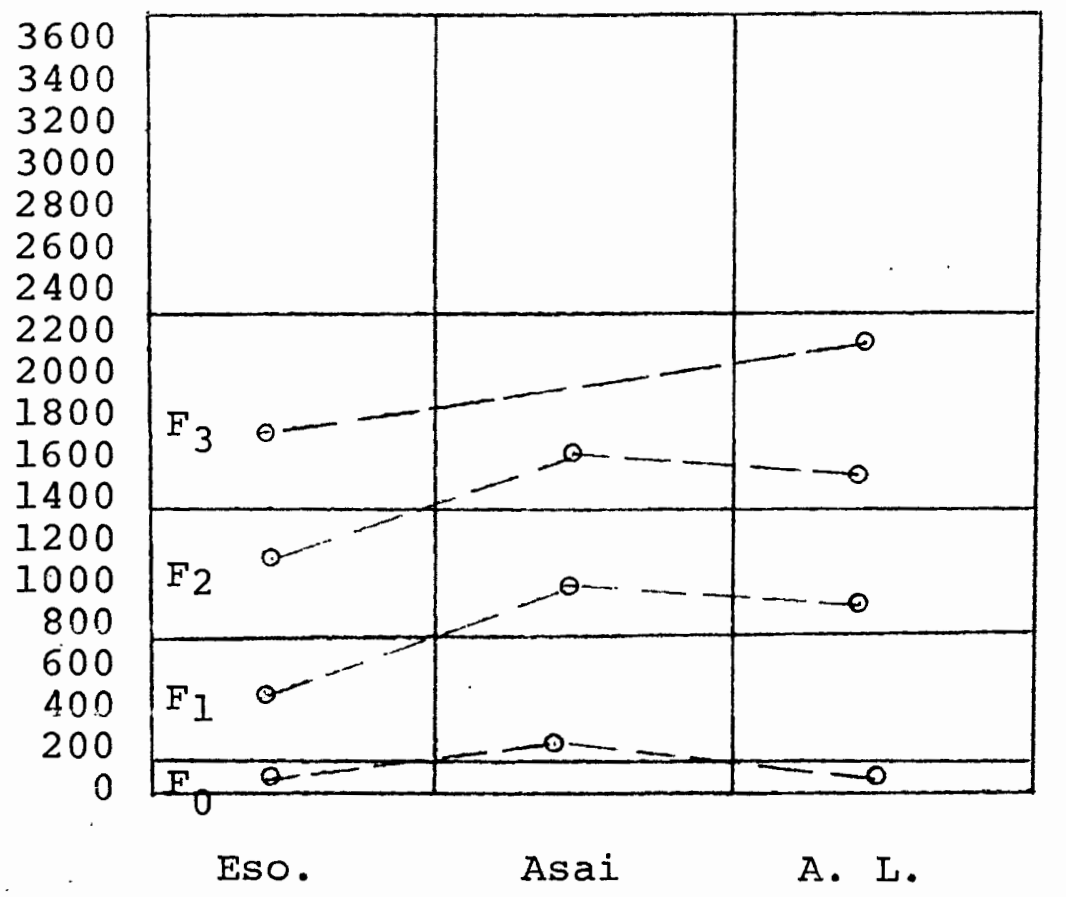

MALE SPEAKERS

$$
F_{0}, F_{1}, F_{2}, F_{3}-/ \alpha /
$$

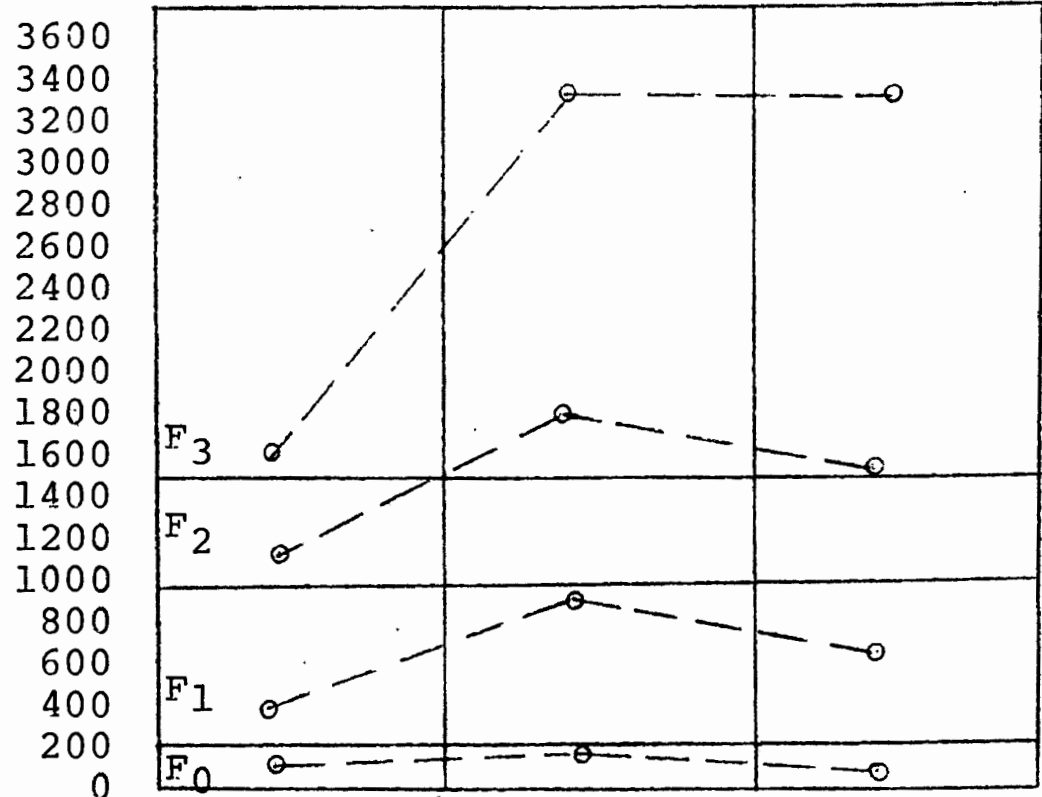

Fso.
A. L.

$$
\mathrm{F}_{0}, \mathrm{~F}_{1}, \mathrm{~F}_{2}, \mathrm{~F}_{3}-/ \mathrm{a} /
$$

Note: Connecting lines denote normal speaker's frequency for $F_{0}, F_{1}, F_{2}, F_{3}$

Figure 4. Comparison of Alaryngeal Speakers to Normal speakers on Fundamental and Formant Frequencies, Vowel /a/.

*No information available for $F_{3}$ for normal female and Asai male subjects. 

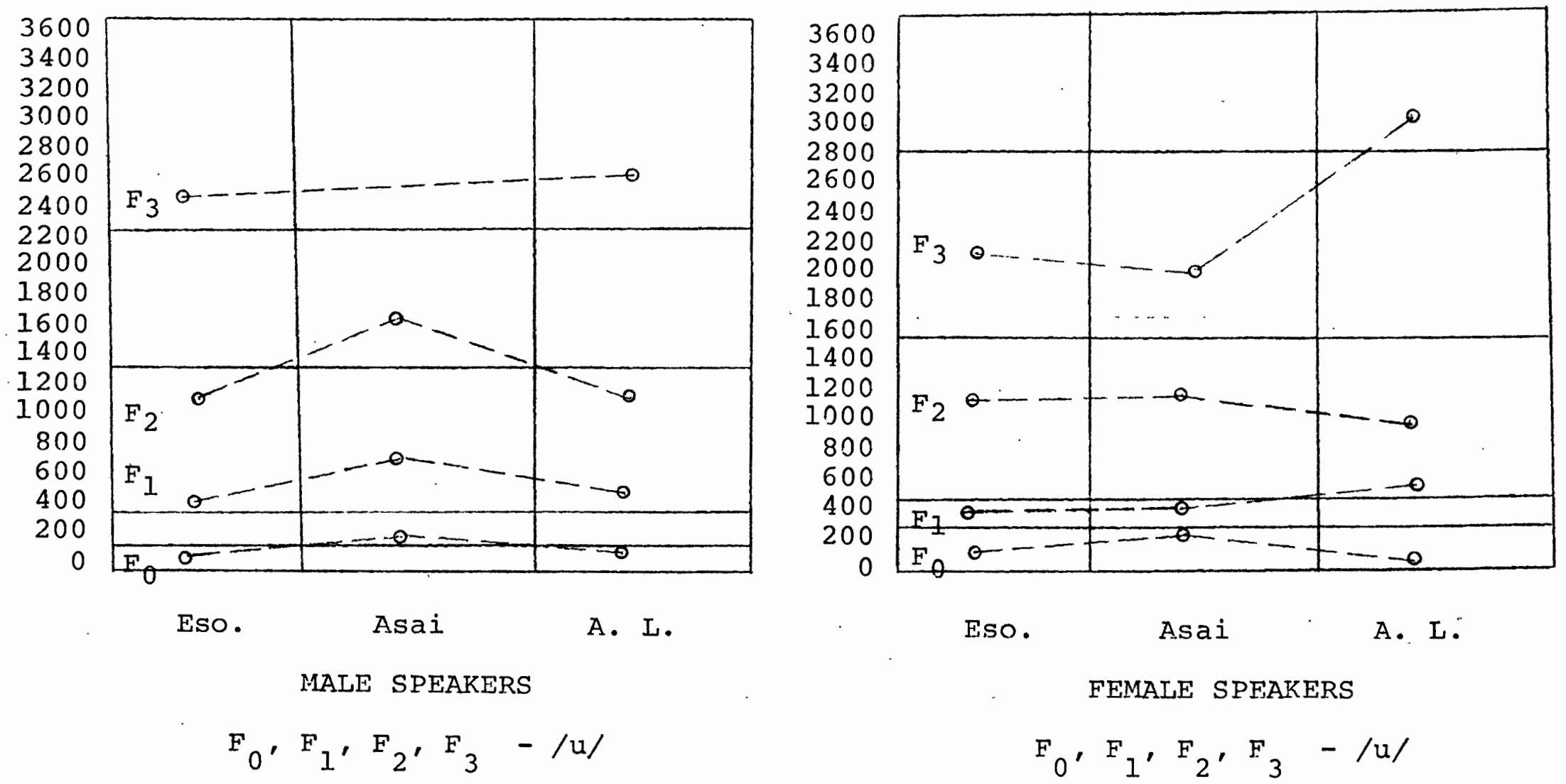

Note: Connecting lines denote normal speaker's Erequency for $F_{0}, F_{1}, F_{2}, F_{3}$

Figure 5. Comparison of Alaryngeal Speakers to Normal speakers on Fundamental and Formant Frequencies, vowel/u/.

*No information available for $\mathrm{F}_{3}$ for Asai male speaker. 

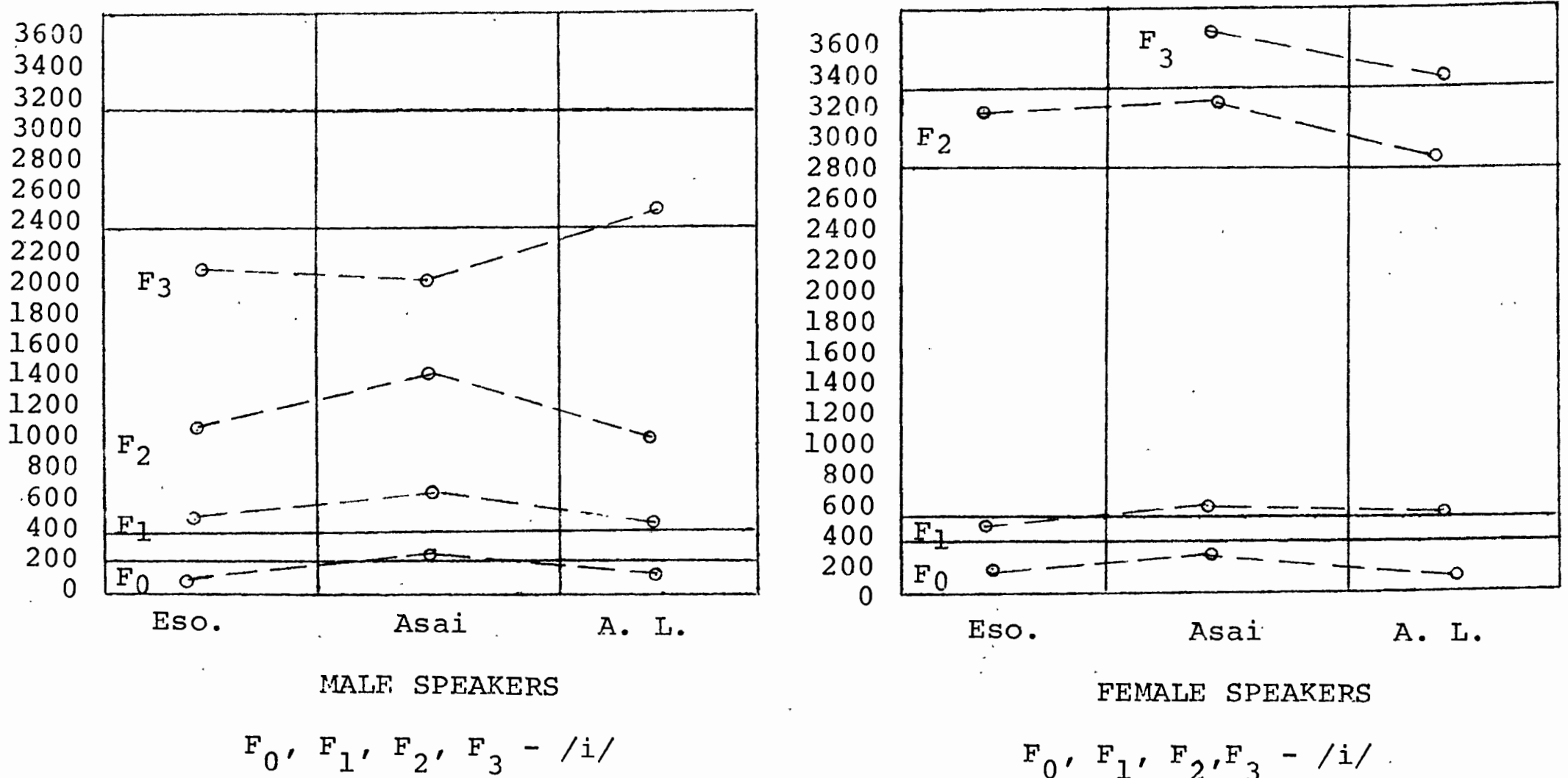

$F_{0}, F_{1}, F_{2}, F_{3}-/ i /$

Note: Connecting lines denote normal speaker's frequency for $\mathrm{F}_{0}, \mathrm{~F}_{1}, \mathrm{~F}_{2}, \mathrm{~F}_{3}$

Figure 6. Comparison of Alaryngeal Speakers to Normal Speaker $s$ on Fundamental and Formant Frequencies, Vowel $/ i /$.

* No information available for $\mathrm{F}_{3}$ for esophageal female speaker. 
TABLE V

VARIABILITY OF FREQUENCIES OF FORMANTS AND FUNDAMENTAL FREQUENCY

MALE SUBJECTS

\begin{tabular}{|c|c|c|c|c|}
\hline VOWEL & $F_{0}$ & $F_{1}$ & $F_{2}$ & $\mathrm{~F}_{3}$ \\
\hline $\begin{array}{l}\text { Normal } \\
\text { Tol } \\
|a| \\
/ \text { u/ } \\
|i|\end{array}$ & $\begin{array}{l}128 \\
120 \\
128-136 \\
136-144\end{array}$ & $\begin{array}{l}725-750 \\
650-750 \\
300 \\
250-300\end{array}$ & $\begin{array}{l}1800-1900 \\
1250-1350 \\
1200-1500 \\
2300-2400\end{array}$ & $\begin{array}{l}2700-2750 \\
2550-2650 \\
2250 \\
3000-3250\end{array}$ \\
\hline $\begin{array}{l}\text { Esophageal } \\
\text { Tol } \\
/ a / \\
/ \mathrm{u} / \\
/ \mathrm{i} /\end{array}$ & $\begin{array}{l}64-80 \\
72-80 \\
72 \\
60-72\end{array}$ & $\begin{array}{l}1000 \\
300-750 \\
350-400 \\
300-350\end{array}$ & $\begin{array}{l}2000-2100 \\
1000-1200 \\
1050-1200 \\
1000-1050\end{array}$ & $\begin{array}{l}3000-3400 \\
1450-2150 \\
2400-2500 \\
17.00-2400\end{array}$ \\
\hline $\begin{array}{l}\frac{\text { Asai }}{\text { Toe }} \\
|a| \\
|u| \\
|i|\end{array}$ & $\begin{array}{l}160-176 \\
152-184 \\
144-168 \\
160\end{array}$ & $\begin{array}{l}800 \\
850-1000 \\
650-750 \\
475-600\end{array}$ & $\begin{array}{l}1350-1650 \\
1550-1600 \\
1500-1700 \\
1250-1450\end{array}$ & $\begin{array}{l}2200-2550 \\
* \\
* \\
2000-2100\end{array}$ \\
\hline $\begin{array}{l}\text { Artificial Larynx } \\
\text { /al } \\
\text { /a/ } \\
/ \mathrm{u} / \\
/ \mathrm{i} /\end{array}$ & $\begin{array}{l}96-104 \\
96-104 \\
104 \\
104\end{array}$ & $\begin{array}{l}775-825 \\
800-950 \\
475-500 \\
300-350\end{array}$ & $\begin{array}{c}1400-1450 \\
1350-1750 \\
950-1300 \\
850-950\end{array}$ & $\begin{array}{l}2200 \\
2050-2300 \\
2625-2650 \\
2400-2500\end{array}$ \\
\hline
\end{tabular}

*denotes no information available 
TABLE VI

VARIABIIITY OF FREQUENCIES OF FORMANTS AND FUNDAMENTAI FREQUENCY

FEMALE SUBJECTS

\begin{tabular}{|c|c|c|c|c|}
\hline VOWEL & $F_{0}$ & $\mathrm{~F}_{1}$ & $\mathrm{~F}_{2}$ & $\mathrm{~F}_{3}$ \\
\hline Normal & & & & \\
\hline $\begin{array}{l}\text { Tal } \\
|a| \\
\mid u / \\
|i|\end{array}$ & $\begin{array}{l}176-200 \\
192 \\
208 \\
208-232\end{array}$ & $\begin{array}{l}800-850 \\
900-1000 \\
375-400 \\
300-400\end{array}$ & $\begin{array}{l}2100-2250 \\
1350-1500 \\
1400-1600 \\
2600-2800\end{array}$ & $\begin{array}{l}2750-2850 \\
* \\
2750-2850 \\
3200-3250\end{array}$ \\
\hline Esophageal & & & & \\
\hline $\begin{array}{l}\mid \text { Toe } \\
|a| \\
|u| \\
|i|\end{array}$ & $\begin{array}{l}160-168 \\
112-136 \\
112-144 \\
104-120\end{array}$ & $\begin{array}{l}750-850 \\
300-350 \\
375-450 \\
300-400\end{array}$ & $\begin{array}{l}2400-2475 \\
1100-1200 \\
1000-1175 \\
3100-3150\end{array}$ & $\begin{array}{l}3550-3650 \\
1500-1675 \\
1900-2375 \\
*\end{array}$ \\
\hline Asai & & & & \\
\hline $\begin{array}{l}\text { Toel } \\
\text { /al } \\
/ u / \\
/ i /\end{array}$ & $\begin{array}{l}160-184 \\
160-168 \\
192-208 \\
184-200\end{array}$ & $\begin{array}{l}750-800 \\
800-900 \\
300-500 \\
350-475\end{array}$ & $\begin{array}{l}2250-2450 \\
1750-1850 \\
1150-1200 \\
3150-3250\end{array}$ & $\begin{array}{l}3000-3450 \\
3250-3400 \\
1950-2000 \\
3500-3600\end{array}$ \\
\hline Artificial Larynx & & & & \\
\hline $\begin{array}{l}\text { Toel } \\
|a| \\
/ \text { il } \\
/ i /\end{array}$ & $\begin{array}{l}80 \\
80 \\
80 \\
80\end{array}$ & $\begin{array}{l}800-900 \\
550-700 \\
500-550 \\
400\end{array}$ & $\begin{array}{r}2300-2400 \\
1400-1500 \\
950-1000 \\
2600-2950\end{array}$ & $\begin{array}{l}3200-3250 \\
3300 \\
3000-3100 \\
3300-3500\end{array}$ \\
\hline
\end{tabular}

*denotes no information available 
speech can be observed by referring to Table IV. The esophageal male speaker shows a considerably lower fundamental frequency as compared with the normal, i.e., the mean fundamental frequency is approximately $70 \mathrm{~Hz}$ for the four vowels produced by the esophageal speaker while approximately $130 \mathrm{~Hz}$ was produced by the normal subject. For the vowel / $/ 2 /$ the esophageal speaker produced formants which are higher in frequency than those of the normal speaker; however, this pattern did not occur for the other vowels. For the vowel $/ a /$, lower formants were found. The vowel / $\mathrm{u} /$ very closely approximates the normal / $\mathrm{u} /$ across the formant range, while /i/ did not follow a particular pattern, but varied greatly. The Asai male speaker showed consistently higher values for both fundamental frequency and formant 1 for all vowels investigated. A mean fundamental frequency of $163 \mathrm{~Hz}$ for the four examined vowels is considerably higher than the normal mean fundamental frequency of $129 \mathrm{~Hz}$. Formant 2 is not consistent with normal, most variant is /i/, in which the frequency is nearly $1000 \mathrm{~Hz}$ lower than the normal. Data on formant 3 for the Asai male is sketchy and inconsistent. In many Asai vowel productions, no third formant could be located on the sonographic display.

The artificial larynx male used a fundamental frequency of approximately $102 \mathrm{~Hz}$ overall. His use of an electronic device negates any need for discussion of fundamental frequency as this factor is controlled by the mechanical 
vibrator. As with the Asai speaker, this subject used higher formant 1 frequencies than the normal speaker, although in no case was there a considerable difference. Formant 2 was found to be inconsistent and showed no trend in variance as compared to normal with only $/ a /$ and $/ u /$ relatively close to normal. Formant 3 values likewise showed a pattern of variance from normal and were very inconsistent.

Examination of the data collected indicates very little relationship among the three types of alaryngeal speech investigated. Fundamental frequencies for the esophageal and Asai speakers vary considerably (artificial larynx not considered for reasons stated above). Relationships among the formant frequency values also varies as illustrated in Figures 3 through 6 , although some vowels produced by the same speakers showed normal patterns. Any further comparisons would be unwarranted by the data.

For the female speakers similar comparisons can be made to those seen in the male subjects. The esophageal female speaker used an average fundamental frequency of approximately $132 \mathrm{~Hz}$, which is considerably below the $202 \mathrm{~Hz}$ found in the female normal speaker. Across all formants, the differences between normal and esophageal speaker were seen to be varied, with no pattern noted. Likewise, no pattern could be found for the fundamental frequency relationships of the individual vowels to their normal counterparts. It must be concluded the esophageal female voice represented here varies 
widely and inconsistently from the normal voice examined. The female Asai speaker studied was noted to have a fundamental frequency of $179 \mathrm{~Hz}$. Of the female alaryngeal speakers, this most closely approximated the normal female voice. For the vowel /u/ all formants were lower, whereas, for the vowel $/ i /$, all formants were higher. For the remaining two vowels studied, $/ 2 \mid$ and $/ a /$, no pattern of variance could be determined.

In examining the results of vowel production of the artificial larynx female subject, it appears / $i /$ is the most like normal production of formants 1,2 , and 3 , with each formant being only slightly elevated from those of the normal subject. The overall picture presented by the artificial larynx female is far less varied than the other two alaryngeal female speakers. The low fundamental frequency is the result of a chosen frequency by the subject in using the mechanical device and does not reflect any physical characteristic of the subject's voice production. The implications of this chosen low fundamental frequency and its effects on formant values are uncertain.

Examination of the data collected on the female alaryngeal speakers shows similarities among all three speakers on the vowel / $/ 2 /$ (see Figure 3). The vowel /a/ (see Figure 4) shows fairly consistent performance on formants 1 and 2 across all speakers; however, formant 3 relationships are widely varied and do not follow the pattern seen in lower 
formants. The third formant of the esophageal speaker is extremely low in relation to the Asai and artificial larynx speakers, and since the normal speaker's formant 3 is not identifiable no relationship to normal can be noted.

The vowel / $/$ / shows inconsistent performance across all speakers on fundamental and all formant frequencies (see Figure 5). As with $/ a /$, formant 3 is particularly varied across alaryngeal speakers, and only the artificial larynx female shows a third formant within range of normal.

Vowel / $i /$ shows quite close relationships to normal at all levels (see Figure 6). Fundamental frequency values follow a pattern established on other vowels with Asai most closely approximating the normal value. Formant 1 values across speakers are all near normal values, while formant 2 values, all somewhat higher than the normal, are more inconsistent with normal. The exception on formant 2 is the artificial larynx speaker, whose performance on all frequencies was seen as very consistent with normal. For formant 3 no values could be determined for the esophageal speaker, and the Asai and artificial larynx speakers show results similar to those seen in the formant 2 relationships to the normal performance.

It can be seen by referring to Figures 3 through 6 that female speakers showed more consistent performances and most closely approximated normal on vowels / $2 /$ and / i/. This differs from results found for male speakers where / $/$ / and 
/a/ seem to most closely approximate normal. The notable exception in the male performances was the esophageal speaker, whose values were very inconsistent with normal. Among female speakers also, the esophageal performance was least predictable when compared to normal values.

\section{DISCUSSION}

The results of this investigation reveal a number of areas in which inconsistency and unpredictable variability predominate. There are several possible explanations for these findings; these explanations, in addition to the small number of subjects, may provide clues to areas of question for further study.

It is possible that the vowels produced by each subject may not have been those vowels modelled in the explanation given to the subject before recording. Individual differences in vowel production were not compensated for by averaging a larger group of subjects, as was the case in the Peterson and Barney study (1952), and thus an individual difference would alter the results of the study. Another factor which must be considered is acoustic noise produced in the vocal tracts of the alaryngeal speakers, in the form of breathiness, aperiodicity of vibration at the level of sound production, and possible stoma noise. This noise factor makes identification of formants difficult in sonographic analysis. Here again, a larger sample population 
may have been effective in overcoming some of these individual problems through averaging values obtained from a 'number of subjects.

When the normal subjects for this investigation were compared with the Peterson and Barney (1952) data, some notable differences were found. (See Tables VII and VIII.) Differences are also very prominent when comparisons are drawn between previously reported studies of esophageal fundamental and formant frequency values, and those found in this

TABLE VII

COMPARISON OF NORMAI SUBJECTS WITH

PETERSON AND BARNEY SUBJECTS

MALE SPEAKERS

\begin{tabular}{lrrrr}
\hline VOWEL & $\mathrm{F}_{0}$ & $\mathrm{~F}_{1}$ & $\mathrm{~F}_{2}$ & $\mathrm{~F}_{3}$ \\
\hline /2e/ Norms & 127 & 660 & 1720 & 2410 \\
\hline P\&B Nal & 128 & 741 & 1850 & 2733 \\
Normaference & +1 & +81 & +130 & +323 \\
Differ & & & & \\
/a/ Norms & 124 & 730 & 1090 & 2440 \\
P\&B Normal & 120 & 716 & 1300 & 2600 \\
Difference & -4 & -14 & +210 & +160 \\
/u/ & & & & \\
P\&B Norms & 141 & 300 & 870 & 2240 \\
Normal & 130 & 300 & 1300 & 2250 \\
Difference & -11 & 0 & +430 & +10 \\
/i/ Norms & & & & \\
P\&B Norms & 136 & 270 & 2290 & 3010 \\
Normal & 138 & 175 & 2358 & 3100 \\
Difference & +2 & -95 & +68 & +90 \\
& & & & \\
\hline
\end{tabular}


TABLE VIII

COMPARISON OF NORMAL SUBJECTS WITH PETERSON AND BARNEY SUBJECTS

FEMALE SPEAKERS

\begin{tabular}{|c|c|c|c|c|}
\hline VOWEL & $\mathrm{F}_{0}$ & $\mathrm{~F}_{1}$ & $\mathrm{~F}_{2}$ & $\mathrm{~F}_{3}$ \\
\hline $\begin{array}{l}\frac{|\alpha e|}{\mathrm{P} \& \mathrm{~B} \text { Norms }} \\
\text { Normal } \\
\text { Difference }\end{array}$ & $\begin{array}{l}210 \\
221 \\
+11\end{array}$ & $\begin{array}{r}860 \\
350 \\
-510\end{array}$ & $\begin{array}{r}2050 \\
2700 \\
+650\end{array}$ & $\begin{array}{r}2850 \\
3216 \\
+366\end{array}$ \\
\hline $\begin{array}{l}\frac{|a|}{P \& B} \text { Norms } \\
\text { Normal } \\
\text { Difference }\end{array}$ & $\begin{array}{l}212 \\
192 \\
-20\end{array}$ & $\begin{array}{l}850 \\
933 \\
+83\end{array}$ & $\begin{array}{l}1220 \\
1416 \\
+196\end{array}$ & $\begin{array}{l}2810 \\
*\end{array}$ \\
\hline $\begin{array}{l}\frac{/ \mathrm{u} /}{\mathrm{P} \& \mathrm{~B}} \text { Norms } \\
\text { Normal } \\
\text { Difference }\end{array}$ & $\begin{array}{l}231 \\
208 \\
-23\end{array}$ & $\begin{array}{r}370 \\
383 \\
+13\end{array}$ & $\begin{array}{r}950 \\
1466 \\
+516\end{array}$ & $\begin{array}{r}2670 \\
2783 \\
+113\end{array}$ \\
\hline $\begin{array}{l}\frac{/ i /}{\mathrm{P} \& \mathrm{~B}} \text { Norms } \\
\text { Normal } \\
\text { Difference }\end{array}$ & $\begin{array}{l}235 \\
221 \\
-14\end{array}$ & $\begin{array}{l}310 \\
350 \\
+40\end{array}$ & $\begin{array}{r}2790 \\
2700 \\
-90\end{array}$ & $\begin{array}{r}3310 \\
3216 \\
-94\end{array}$ \\
\hline
\end{tabular}

investigation. Results of several studies have shown esophageal fundamental frequency values to shift downward from normal. This trend also was reflected in the performance of both male and female esophageal speakers in this investigation. Formant frequency values for the vowel / $\mathrm{u} /$ for the male esophageal speaker are most similar to those found in the studies of esophageal speakers by Sisty and Weinberg (1972). Formant values for the other three vowels were not as similar, with /a/ being the least comparative. Female esophageal values in the Sisty and Weinberg (1972) study 
show some similarities to the female esophageal speaker in this investigation of $F_{1}$ and $F_{2}$ of $/ i /$ and $/ u /$. The vowels $|\partial|$ and $|a|$, however, are not comparable.

The Asai voice has not been as widely studied; however, the $97.08 \mathrm{~Hz}$ mean fundamental frequency for Asai males reported by Curry and snidecor (1973) differs considerably from the $163 \mathrm{~Hz}$ mean fundamental frequency of the male Asai speaker in this investigation. The two female Asai speakers seen by Curry and snidecor (1973) showed such disparity that no average was determined. One Curry and snidecor (1973) female showed a mean fundamental frequency of $150 \mathrm{~Hz}$. The female Asai speaker in this investigation showed a mean fundamental frequency of $180 \mathrm{~Hz}$ for the vowels studied. This suggests that a higher fundamental frequency is available to the female Asai speaker, thus a closer approximation to normal female fundamental frequency.

Phonetic context of the vowels in this investigation may have resulted in variance from previous studies. Peterson and Barney (1952) imbedded the vowels they studied between consonants $/ h /$ and $/ d /$, to form monosyllable words, e.g., /hid/, /hud/, and /hxd/. The /h/ phoneme is not available to laryngectomees as production occurs at the level of the vocal folds. The phoneme / $d /$ would have created a glide characteristic to the sonographic display due to its voiced production. This would have made sonographic analysis of the target vowels more complicated. Unvoiced consonants 
isolate the vowel serving to make it a distinct entity, thus facilitating sonographic analysis. The subjects in the current study produced the four vowels studied within the context of consonants $/ t /$ and $/ p /$. The initiating phoneme / $t /$ was chosen because it is a plosive and this feature aids the laryngectomee in initiating phonation. The arresting consonant /p/ was chosen primarily for its voiceless component. The phonetic contextual difference described may have altered the results as compared with Peterson and Barney (1952). This difference, however, would not have an effect upon comparisons of the alaryngeal speakers with normals in the current study.

It is apparent, one must use caution in drawing conclusions from comparisons of single members of populations of alaryngeal speakers with single members of the normal speaking population. Nonetheless, from the results obtained in this investigation, it may be suggested that quantitative data are useful sources of information for consideration when selecting the type of alaryngeal voice to be used by a prospective laryngectomee. Information on fundamental frequency relationships to the normal fundamental frequency of male and female speakers is of importance.

If data on the female alaryngeal speakers are representative of a larger population, the Asai speaker most closely approximated the normal speaker in fundamental frequency. In view of the frequent confusion in the perception 
of male and female voices in esophageal speakers (Curry and Snidecor, 1961), this higher fundamental frequency could be influential in selecting the Asai procedure with the purpose of obtaining a fundamental frequency more similar to normal female fundamental frequencies. 


\section{CHAPTER V \\ SUMMARY AND IMPLICATIONS}

\section{SUMMARY}

Laryngectomy, as a treatment for malignant laryngeal lesions, requires the patient to seek a substitute method of producing speech. Three types of alaryngeal speech were described: esophageal, Asai, and artificial larynx. One consideration in deciding which mode of speech is best for the patient is how closely each type of alaryngeal speech approximates normal.

This investigation was an objective examination of esophageal, Asai and artificial larynx speech as compared with normal in males and females. Comparisons were based on production of four vowels $/ i /,|2|, \mid a /, / u /$. Eight subjects were selected, one male and one female in each type of alaryngeal speech. All speakers were recorded producing the four vowels three times. Each production was analyzed sonographically to determine fundamental frequency and formants 1,2 , and 3 .

The following information was obtained to answer the questions posed:

1. What is the difference in fundamental frequency and formants 1,2 , and 3 of four vowels produced by esophageal 
speakers and normal speakers?

Fundamental frequencies produced by male and female esophageal speakers were 60 and $70 \mathrm{~Hz}$ lower than their normal counterparts, respectively. Formant frequency values for both esophageal speakers showed little relationship to normal, varying both higher and lower in no predictable pattern.

2. What is the difference in fundamental frequency and formants 1, 2, and 3 of four vowels produced by Asai speakers and normal speakers?

The male Asai speaker produced a fundamental frequency approximately $30 \mathrm{~Hz}$ higher than the normal male speaker. Formant 1 was found to be lower than normal; however, this trend did not continue in formants 2 and 3 .

Female Asai fundamental frequency values, only $20 \mathrm{~Hz}$ lower than normal, suggest that the Asai technique may provide the female laryngectomee with the closest approximation to normal.

3. What is the difference in fundamental frequency and formants 1, 2, and 3 of four vowels produced by speakers using electronic vibratory devices and normal speakers? Laryngectomees using an artificial larynx select the fundamental frequency they desire in operating the mechanical device. These chosen values are considerably lower than normal. As with the other alaryngeal speakers, formant values were scattered above and below normal formant frequencies.

4. What is the difference between male and female 
production of these vowels in each of the four modes of speech?

Male alaryngeal speakers showed much greater consistency in the production of fundamental frequency over the range of the four vowels. Female alaryngeal speakers varied as much as $53 \mathrm{~Hz}$ from one vowel to another. Artificial larynx speakers are not considered because of the mechanical production of fundamental frequency.

5. What is the difference between esophageal, Asai and electronic vibratory device speakers for the four vowels examined?

Esophageal speakers produce a low fundamental frequency when compared to Asai speakers. Artificial larynx also produces a low fundamental frequency, but this is at the discretion of the user. Data on formant frequencies were inconsistent and provided minimal information.

Conclusions derived from this investigation must be guarded due to the small sample population. If the data on these subjects is representative of larger populations, it may be inferred that the fundamental frequency of female Asai speakers is considerably closer to normal than the other two types of alaryngeal speech studied. Male alaryngeal speakers appear to have a broader choice of fundamental frequency ranging above and below normal values.

Further study is suggested on the quantitative aspects of alaryngeal speech using a considerably larger population 
of subjects. Extreme variations noted in some instances in formant relationships only clarify the need to minimize individual differences through a larger sample.

\section{IMPLICATIONS}

Clinical

The lack of conclusive evidence found in this investigation points strongly toward a need for further research before clinical implications may be drawn. Certain other aspects of the various alaryngeal speech methods should be considered by the physician and speech pathologist before the final determination is made as to what form of speech the new laryngectomee will adopt. Considerations such as length of time to learn the new process, motivation for learning a new mode of speech, attitude of the patient and others important in the patient's environment, occupational needs, and financial needs must be part of the decisionmaking process.

All forms of alaryngeal speech sound different than the so-called normal voice. While Asai speech is somewhat breathier, it does provide the laryngectomee with immediate voice use following the surgical procedures with no learning process before communication can commence. A major consideration for the prospective Asai patient is the need for three surgical procedures before voice can be used. The length of time between operations varies, but an average of three 
months from laryngectomee to speech is common. Additionally, there is the disadvantage of requiring that a finger be placed over the stoma in order to direct air through the Asai "tube"; this factor should be considered as it may be troublesome to some patients.

Esophageal speech, long the preferred method of alaryngeal speech by physicians and speech pathologists, is not always successfully learned and must be placed in the proper perspective as a learned skill. It often requires several years to achieve. There is less surgical intervention necessary in esophageal speech, and this may be an advantage for some patients.

Artificial larynx speech using a handheld electronic vibratory device is only recently becoming an acceptable substitute for voice. While some learning must take place to produce acceptable speech easily, there is no need to learn air injection as with esophageal speech. This device is used by some patients as a means of communication until esophageal speech can be mastered, and by some, as a permanent means of oral communication.

All factors mentioned must be considered by patient, physician, and speech pathologist in order to make the wisest choice for the new laryngectomee. In addition, general physical and mental health and the severity of the malignancy and resultant surgical intervention are factors which will affect selection of speech mode. Before clinical decisions can be 
aided by the objective data obtainable by vocal analysis, a much larger and more varied population of laryngectomees of all types will need to be examined.

$\underline{\text { Research }}$

It is recommended that this investigation be conducted on a larger scale, using alaryngeal speakers with a range of vocal skills from poor to good. In this way, there is less chance the data will be contaminated by individual differences. It would be interesting to note the various formant relationships that would arise in a larger study, and their correlation with normal formant relationships. It is this aspect of vocal analysis that is most intriguing because it offers insight into the actual characteristics of the vowels produced.

It would be illuminating to include, within another quantitative investigation, identification of the vowels examined by subjecting them to listener judgment. The possibility of alteration of results due to differences between those vowels requested and those actually produced by alaryngeal speakers could possibly be lessened by having panels of listeners identify vowels they perceive prior to subjecting the vowels to sonographic analysis.

The obvious need for more research in all areas of alaryngeal speech, especially formant construction is clear. More and more laryngectomees are surviving surgery each year and requiring professional assistance with decisions regarding 
a new voice. While objective data of the nature suggested cannot be the only criteria for decision-making, it can be extremely useful if provided by a representative sample of significant size. 


\section{BIBLIOGRAPHY}

ASAI, R., Laryngoplasty After Total Laryngectomy. Archives of Otolaryngology, 95, 114-119 (1972).

BOGERT, Bruce and Peterson, G. E., The Acoustics of Speech. Handbook of Speech Pathology, L. E. Travis, ed., New York: Appleton-Century-Crofts (1957).

BOONE, D., The Voice and Voice Therapy. Englewood Cliffs, New Jersey: Prentice-Hall, Inc. (1971).

BROAD, D. J. and Peterson, G. E., The Acoustics of Speech. Handbook of Speech Pathology, L. E. Travis, ed., New York: Appleton-Century-Crofts (1971).

COLEMAN, R. O., Male and Female Voice Quality and Its Relationship to Vowel Formant Frequencies. Journal of Speech and Hearing Research, 14, 565-577 (1971).

CURRY, E. T. and Snidecor, J. C., Physical Measurement and Pitch Perception in Esophageal Speech. Laryngoscope, $71,415-424$ (1961).

CURRY, E. T., Snidecor, J. C. and Isshiki, N., Fundamental Frequency Characteristics of Japanese Asai Speakers. Laryngoscope, 83, 1759-1763 (1973).

DENES, P. B. and Pinson, E. N., The Speech Chain. Bell Telephone Laboratories (1963).

DIEDRICH, W. M. and Youngstrom, K. A., Alaryngeal Speech. Springfield, Illinois: Charles C. Thomas, Publisher (1966).

FAIRBANKS, G., Voice and Articulation Drillbook, second edition. New York: Harper and Row, Publishers (1960).

FROESCHELS, E., Twentieth Century Speech and Voice Correction. New York: Philosophical Library, Inc. (1948).

GRAY, G. W. and Wise, C. M., The Bases of Speech. New York: Harper and Brothers, Publishers $(\overline{19} 5 \overline{9})$.

HANLEY, T. D. and Thurman, W. L., Developing Vocal Skills. New York: Holt, Rinehart and Winston (1962). 
HOLLIEN, H., Vocal Pitch Variation Related to Changes in Vocal Fold Length. Journal of Speech and Hearing

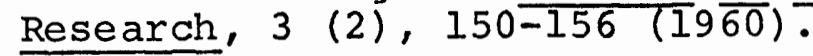

HOLLIEN, H., Vocal Fold Thickness and Fundamental Frequency of Phonation. Journal of Speech and Hearing Research, 5 (3), 237-243 (1962).

HOLLIEN, H. and Curtis, J., A Laminagraphic Study of Vocal Pitch. Journal of Speech and Hearing Research, 3 (4), 361-371 (1960).

KAPLAN, H. M., Anatomy and Physiology of Speech. New York: McGraw-Hill Book Company (1971).

KARLAN, M. S., Two Stage Asai Laryngectomy Utilizing a Modified Tucker Valve. American Journal of Surgery, 116, 597-599 (1968).

MARSHALL, R. C., Conversion from Asai to Esophageal Speech. Journal of Speech and Hearing Disorders, 37, 262-266 (1972).

MILLER, A. H., First Experiences with the Asai Technique for Vocal Rehabilitation After Total Laryngectomy. Annals of Otology, Rhinology and Laryngology, $76,829-8 \overline{33}$ (1967).

MILLER, A. H., Four Years Experience with the Asai Technique for Vocal Rehabilitation for the Laryngectomized Patient. Journal of Laryngology and Otology, 85, 567576 (1971).

MYSAK, E. D., Pitch and Duration Characteristics of Older Males. Journal of Speech and Hearing Research, 2 (1), $46-54$ (1959).

PERKINS, W. H., Speech Pathology, An Applied Behavioral Science. St. Louis: The C. V. Mosby Co. (1971).

PETERSON, G. E. and Barney, H. L., Control Methods Used in a Study of the Vowels. Journal of the Acoustical Society of America, $24,175-18 \overline{4(1952)}$.

POTTER, R. K., and Peterson, G. E., The Representation of Vowels and Their Movements. Journal of the Acoustical

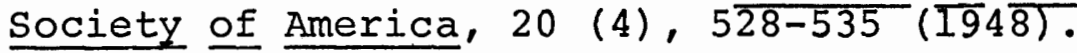

POTTER, R. K. and Steinberg, J. C., Toward the Specification of Speech. Journal of the Acoustical Society of America, $22, \overline{807-820}$ (1950). 
SCHULTHESS, G. V., Pseudoepiglottis and Pseudoglottis from Pedical Skin Flap. Acta Otolaryngologica, 72, 225228 (1971).

SHIPP, T., Frequency, Duration, and Perceptual Measures in Relation to Judgments of Alaryngeal Speech Acceptability. Journal of Speech and Hearing Research, 19, 417-422 (1967).

SISTY, H. I. and Weinberg, B., Formant Frequency Characteristics of Esophageal Speech. Journal of speech and Hearing Research, 15, 439-448 (1972).

SNIDECOR, J. C., and Curry, E. T., How Effectively Can the Laryngectomee Expect to Speak? Laryngoscope, 70, 62$67(1960)$.

SNIDECOR, J. C., Speech Rehabilitation of the Laryngectomized. Springfield, Illinois: Charles C. Thomas, Publisher (1968).

SNIDECOR, J. C., Speech Without a Larynx. Handbook of Speech Pathology, L. E. Travis, ed., New York: AppletonCentury-Crofts (1971).

WEINBERG, B. and Bennett, S., A Study of Talker Sex Recognition of Esophageal Voices. Journal of Speech and Hearing Research, 14 (2), 39 1-395 (1971).

WEINBERG, B. and Bennett, S., Selected Acoustic Characteristics of Esophageal Speech Produced by Female Laryngectomees. Journal of Speech and Hearing Research, 15, $211-216 \quad(1972)$.

WEINBERG, B. and Bennett, S., A Comparison of the Fundamental Frequency Characteristics of Esophageal Speech Measured on a Wave-By-Wave and Averaging Basis. Journal of Speech and Hearing Research, 15, 351-355 (1972).

Zemlin, W. R., Speech and Hearing Science, Anatomy and

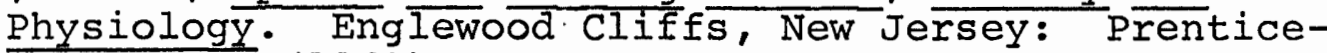
Hall, Inc. (1968). 


\section{EXAMPLES OF SONOGRAPHIC REPRESENTATION OF NORMAL AND ALARYNGEAL SPEAKERS PRODUCTION OF VOWEL / DE/}

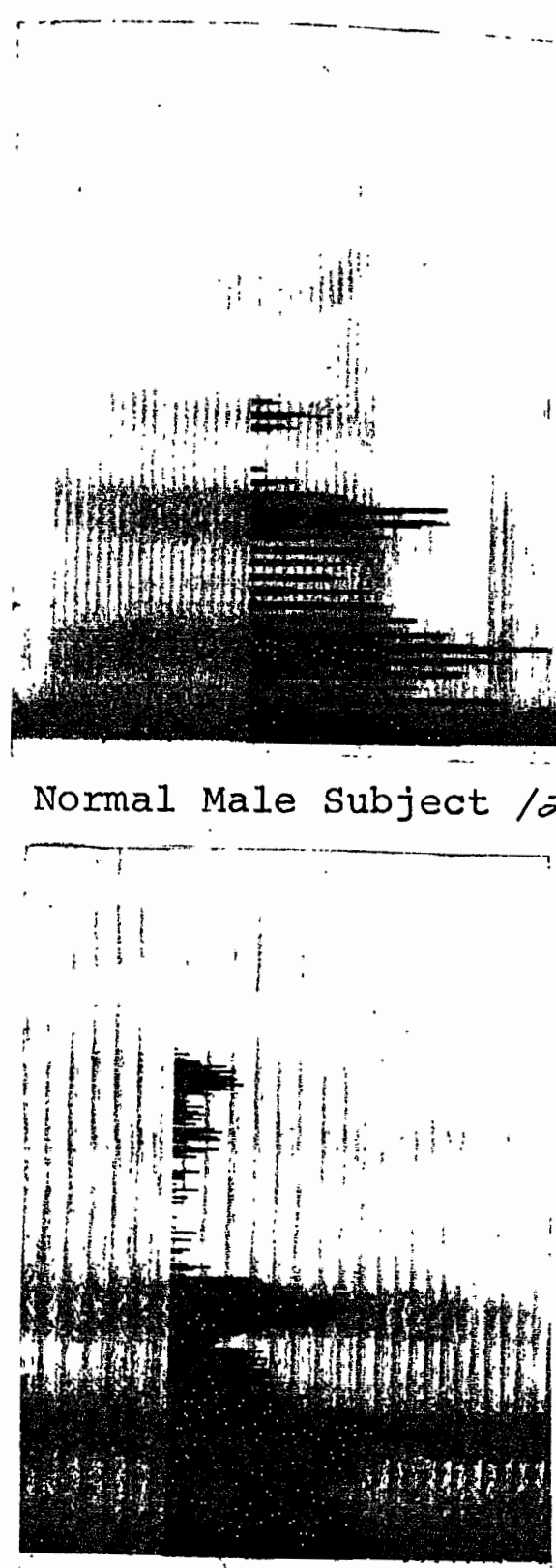

Esophageal Male subject /

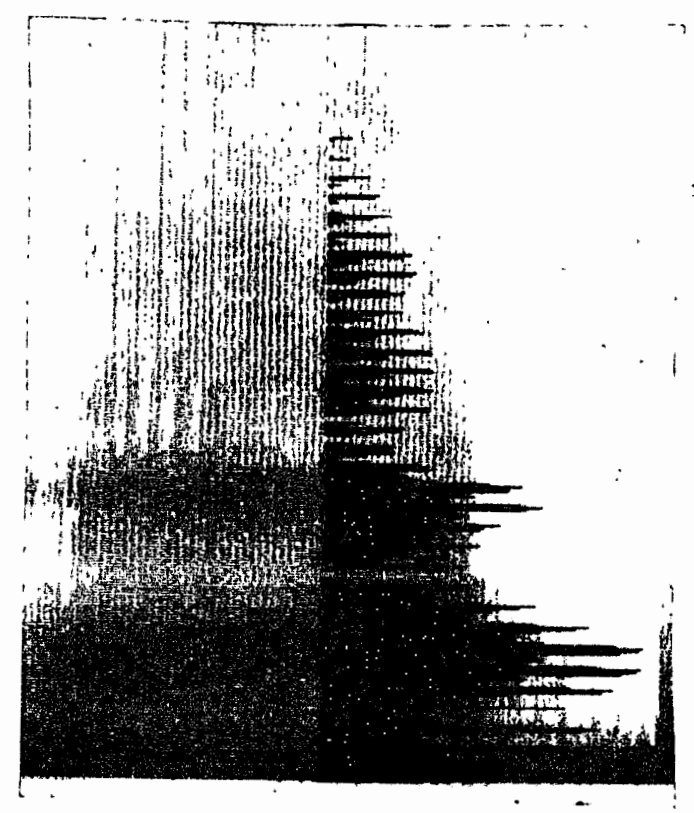

Normal Female subject / oe/

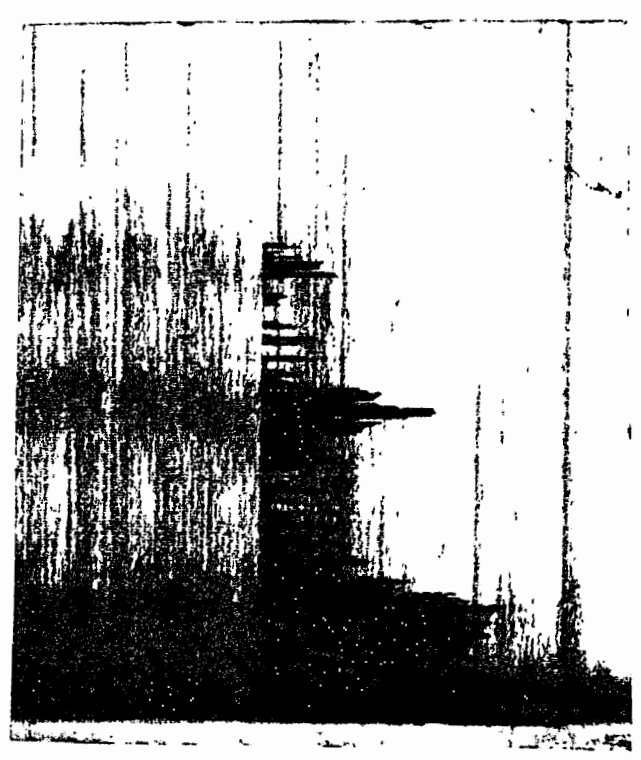

Esophageal Female subject / $2 /$ 

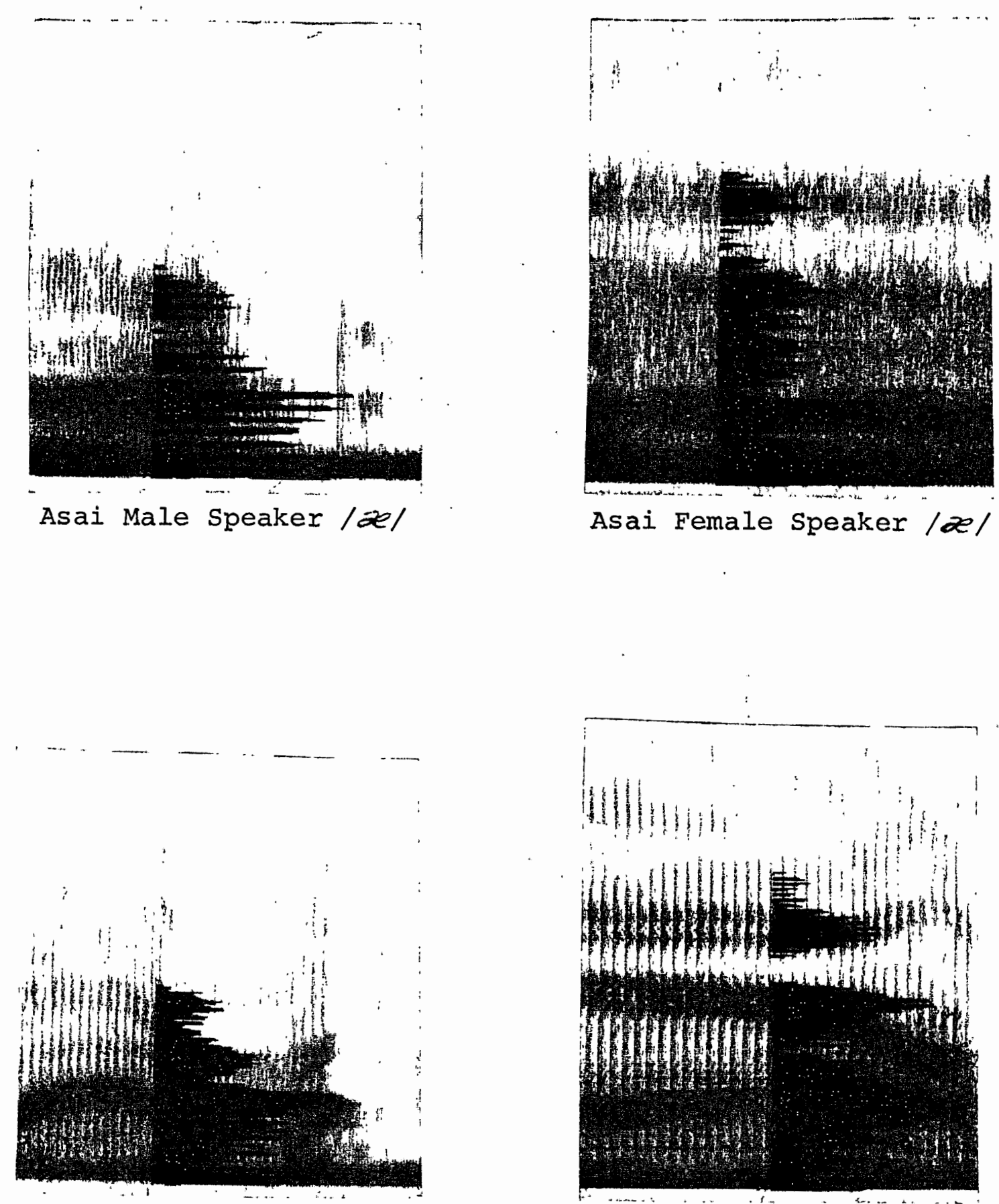

Artificial Larynx Male Speaker /zel

Artificial Larynx Female Speaker loel 


\section{APPENDIX B}

1. The following are the specifications for Kay Sonograph Model 6061B, used in this investigation as described on page 22 .

\section{SPECIFICATIONS}

Frequency range:

Displays available:

Analysis time:

Effective resolution:

AGC range:

Frequency calibration:

Response:

Recording time:

Amplifier characteristics:

Input impedance:

Recording medium:

Microphone supplied:
85 to $16,000 \mathrm{~Hz}$ in two ranges

Frequency-vs-amplitude-vs-time (conventional)

Frequency-vs-amplitude-vs-time (contour)

Amplitude-vs-frequency

Amplitude-vs-time

1.3 minutes

$80-8000 \mathrm{~Hz} 45$ and $300 \mathrm{~Hz}$

$160-16000 \mathrm{~Hz} .90$ and $600 \mathrm{~Hz}$

Variable 20 to $40 \mathrm{~dB}$ down to 10

Switchable at 50,500 , or 1000 $\mathrm{Hz}$ intervals

* $2 \mathrm{~dB}$ over entire range $80-8000 \mathrm{~Hz} 2.4 \mathrm{sec}$. $160-16000 \mathrm{~Hz} 1.2 \mathrm{sec}$.

Flat or 13 dB high-frequency pre-emphasis

200,600 , or $10,000 \Omega$, Switchable

Nickle-cobalt plated turntable

Altec-Lansing 681A dynamic 
Power supply:

Dimensions :

Weight:
$117 \mathrm{~V}, 50 / 60$ CPS, 100 W., Regulated

$25^{\prime \prime} \mathrm{h} \times 20 " \mathrm{w} \times 18 \frac{1}{2} " \mathrm{~d}$

125 lbs. approx.

2. The following are specifications for the Uher tape recorder, Model 4000 Report- $I$, as described on page 21 .

Tape Speed:

Frequency Response:

Dynamic Range:

Wow and Flutter:
$33 / 4$ inches per second $40-16,000 \mathrm{~Hz}$ at $33 / 4$ ips

$56 \mathrm{~dB}$

\pm 0.158 at $7 \frac{1}{2}$ ips 